\title{
1 Crop rotation and agri-environment schemes determine bumblebee communities via
}

\section{2 flower resources}

3 Riho Marja ${ }^{1, *}$, Eneli Viik ${ }^{2}$, Marika Mänd ${ }^{3}$, James Phillips ${ }^{4}$, Alexandra-Maria Klein ${ }^{5}$, Péter

4 Batáry ${ }^{6,7}$

5

$6 \quad{ }^{1}$ Estonian Environment Agency, Rõõmu tee St. 2, Tartu 50605, Estonia.

$7 \quad{ }^{2}$ Agricultural Research Centre, Teaduse St. 4/6, Saku 75501, Estonia.

$8{ }^{3}$ Institute of Agricultural and Environmental Sciences, Estonian University of Life Sciences,

9 Kreutzwaldi St. 5, Tartu 51014, Estonia.

$10{ }^{4}$ School of Environment and Technology, University of Brighton, Cockcroft Building, Lewes

11 Road, Brighton BN2 4GJ, United Kingdom.

$12{ }^{5}$ Nature Conservation and Landscape Ecology, University of Freiburg, Tennenbacher 4,

13 Freiburg D-79106, Germany.

$14{ }^{6}$ Agroecology, University of Goettingen, Grisebachstr. 6, Göttingen D-37077, Germany.

$15{ }^{7}$ GINOP Sustainable Ecosystems Group, MTA Centre for Ecological Research, Klebelsberg

16 Kuno u. 3, 8237 Tihany, Hungary.

17

18 *Corresponding author: Tel.: +372 5225725. Fax:+3727 422180. E-mail: rmarja@ut.ee

20 Running title: Crop rotation determines bumblebee communities

21

22 Word count of summary: 313

Word count of main text: 4203

23 Acknowledgements word count: 126

Word count of references: 1139

24 Word count of legends: 594

Number of figures: 4

25 Number of references: 41

Number of tables: 1 


\section{Abstract}

27 1. In many parts of the world, farmland pollinators decreased significantly during the last half 28 of the $20^{\text {th }}$ Century mainly due to land use changes and agricultural intensification.

29 2. We studied the effect of different typical crop rotations and agri-environment schemes 30 (AES) on bumblebee diversity in Estonia. We compared species abundances between four 31 crop rotation types [cereal rollover (no change from one year to the next), cereal to mass 32 flowering crops (hereafter MFC), MFC rollover, and MFC to cereal fields] where all counts 33 were conducted in the second year, and in three farming types (conventional farming, organic 34 farming and environmentally friendly management).

35 3. We surveyed bumblebees and flower cover along 401 field margins in five consecutive 36 years, and recorded twenty species and more than 6000 individuals. Abundances of long37 tongued and threatened bumblebee species were higher at the field margins of cereal rollover 38 fields than for the other three crop rotation types. In addition, cereal rollover field margins 39 had higher abundances of medium colony species, generalists, and forest scrub species than 40 MFC rollover and MFC to cereal or cereal to MFC field margins. Bumblebee species richness 41 was higher at the field margins of both AES types than those of conventional farming.

42 However, in general the strongest driver of bumblebee presence was flower cover. 4. Higher bumblebee abundances in cereal rollover field margins were probably owing to a concentration effect there and/or a dilution effect into MFC fields. Both AES schemes supported increasing flower cover in field margins and thereby diversity of bumblebees,

46 indicating positive AES impacts upon wild pollinators.

47 5. Synthesis and applications. Crop rotation and AES determine bumblebee richness and abundance via the availability of flower resources, but crop rotation constrains bumblebees 
50 for these management options. Crop rotation could be a simple, but efficient solution to

51 increase the biodiversity of agricultural landscapes.

52

53 Keywords: agri-environment schemes, biodiversity, bumblebee, concentration effect, crop

54 rotation, dilution effect, functional traits, land use, organic management, pollinator 


\section{Introduction}

Bumblebees, among other pollinating insects, contribute to wild plant and crop pollination, and therefore to plant biodiversity and food production (Kremen et al., 2007). Pollination by bumblebees is known to increase the yields of almost 40 crops (Goulson, 2010). Thirty-five percent of global crop production depends, to a degree, on pollinators (Klein et al., 2007), and the global annual economic value of insect pollination is estimated to be between 215-529 billion dollars (IPBES, 2016). Therefore, conservation of farmland pollinators is one of the key challenges of global crop production (Potts et al., 2016).

Industrial agriculture has caused remarkable declines in the diversity and abundance of native flowers and semi-natural habitats, which in turn has caused decreases of wild pollinators, particularly long-tongued bumblebees (Goulson, Lye \& Darvill, 2008). Based on a recent IUCN report, $46 \%$ of bumblebee species populations in Europe have declined (Nieto et al., 2014). Drivers of the decline in pollinators include landscape homogenization, land-use changes (e.g. the loss of semi-natural habitats and the increase in the area of cereal crops) and the increasing use of synthetic pesticides and fertilizers (Winfree et al., 2009; Potts et al., 2010; Bommarco et al., 2012; Goulson et al., 2015). A reduction in the number of small-scale farms has resulted in a decline in crop diversity and the loss of field margins (Sutcliffe et al., 2015). Agri-environment schemes (AES), such as set-aside semi-natural habitat, organic farming, and wildflower strips for pollinators, have been developed and introduced in the European Union since the late 1980 s as a tool to address the negative environmental impacts, including declines in biodiversity, of large-scale agricultural intensification (Batáry et al., 2015).

Across the EU, the effectiveness of AES in terms of species conservation has been questioned owing to goals remaining unachieved as a consequence of a lack of targeting (Hole et al., 2005; Kleijn et al., 2011). Nonetheless, there is evidence of a positive effect of 
many AES upon bumblebee abundances (recently e.g., Carvell et al., 2015; Wood et al., 2015). However, AES availability and utilisation might not be enough to halt and reverse declines in bumblebees and particularly threatened species. Therefore, agricultural intensity as well as landscape structure are also important factors with regard to conservation efforts (Tscharntke et al., 2005, 2012).

Mass-flowering crops, such as clover species and oilseed rape, are significant food resources for bumblebees and at the same time benefit from being pollinated. E.g. in Northern Europe, sweet and red clover, which have deep corolla, benefit from being pollinated by longtongued bumblebee species (Westphal, Steffan-Dewenter \& Tscharntke, 2003; Wood, Holland \& Goulson, 2015). In addition, resource continuity (Blüthgen \& Klein, 2011) is important, because mass-flowering crops are not always available to bumblebees during their lifecycles. Therefore, the availability of wild flowers, especially those with deep corolla, is an important driver of bumblebee diversity and population development (Williams \& Osborne, 2009; Williams et al., 2015).

There is a knowledge gap regarding how temporal land-use change affects bumblebees. To the best of our knowledge, this is the first multi-year study to evaluate the effect of crop rotation on bumblebee communities. We investigated the impact of four different common crop rotation types on bumblebee species richness and abundance, including comparisons between species with different functional traits (tongue length, threat status, colony size, habitat preference), during 2010-2014. In Estonia, crops are usually rotated every second year, e.g. after being a cereal field for one or two years, there will be a rotation to mass flowering crops or grasslands and vice versa. Hence, the overarching question is how does the type of crop rotation determine the following year's bumblebee community (species richness, total abundance, and tongue-length/threat status/colony size/habitat preference group abundances)? We hypothesized that bumblebee species richness and abundance are higher in 
105 the field margins of mass-flowering crops than in the field margins of cereal crops, regardless

106 of the previous year's crop in those fields (illustrative photos are shown in Fig. S1,

107 Supporting Information). In addition, we hypothesized a positive effect upon bumblebees of

108 organic and environmentally friendly management compared to conventional farming. We

109 collected data to test whether crop rotation and/or AES benefit bumblebees, and to identify

110 the possible drivers of bumblebee abundances (e.g., concentration or dilution effects

111 depending on the crop rotation type).

112

\section{2. Materials and methods}

114 2.1. Monitoring areas

115 We sampled true bumblebees Bombus ssp. (hereafter bumblebees) as part of an ongoing

116 evaluation of AES under the framework of the Estonian Rural Development Plan 2007-2013

117 (Agricultural Research Centre, 2015). Two regions of Estonia were studied: Põlva, Võru and

118 Valga counties (hereafter referred to as Southern Estonia; centre coordinates $57^{\circ} 52^{\prime} \mathrm{N}$,

$11926^{\circ} 57^{\prime} \mathrm{E}$ ) and Lääne-Viru, Järva and Jõgeva counties (hereafter Northern Estonia; centre

120 coordinates $59^{\circ} 4^{\prime} \mathrm{N}, 26^{\circ} 12^{\prime} \mathrm{E}$; a map of the study areas is available in Fig. S2, Supporting

121 Information). These regions were selected based on differences in agricultural yields, AES

122 uptake, and landscape structure. Southern Estonia has a more diverse landscape and lower

123 yields (average cereal yield over 2004-2013 was $2792 \mathrm{~kg} / \mathrm{ha}$ ). Northern Estonia is

124 characterized by larger fields, a more open landscape, and high yields by Estonian standards

125 (average cereal yield for 2004-2013 was $3011 \mathrm{~kg} / \mathrm{ha}$ ). Additional information about the

126 regions, and selection of study farms, is available in Marja et al. (2014).

127 In each region 11 organic, 11 environmentally friendly managed (both had five-year

128 AES obligations with the possibility to prolong the obligation to six years, started in 2009),

129 and 11 conventionally managed farms (non-AES) were surveyed, i.e. 66 in total. One of the 
130 aims of environmentally friendly management scheme is to promote farmland biodiversity,

131 with the major requirements of farmers being to allocate a minimum of $15 \%$ of arable land

132 (including rotational grasslands) to legumes, use diversified crop rotation, take soil samples to

133 determine optimal fertilizer requirements and create a fertilization plan, maintain/create

134 permanent grassland field margins (2-5 m wide), not use black fallow (fallow land with bare

135 soil, where the height of weeds does not exceed $5 \mathrm{~cm}$ ), protect landscape elements, and limit

136 glyphosate applications. Organic farmers followed the Organic Farming Act by not using any

137 synthetic pesticides or GMOs, and restricting their use of most mineral fertilizers. Detailed

138 information about AES requirements and conventional farming rules is provided in Table S1,

139 Supporting Information.

\subsection{Biodiversity survey and study design}

142 Fieldwork for the evaluation of AES measures was carried out during the summers of 2010-

143 2014. Every year, each transect was surveyed three times (once in June, July, and August).

144 The first visit was made during the $23^{\text {rd }}-30^{\text {th }}$ of June, the second visit from the $15^{\text {th }}-28^{\text {th }}$ of

145 July, and the third between the $12^{\text {th }}-23^{\text {rd }}$ of August. Bumblebees were surveyed by walking

146 slowly along a $2 \mathrm{~m}$ wide and $500 \mathrm{~m}$ long transect, of which $400 \mathrm{~m}$ was permanent between

147 years and located in field margins (usually permanent grassland strips between the field and a

$148 \mathrm{road} /$ other field/ditch/forest etc., or if the margin was narrow, occasionally also on the edge of

149 a cropped field), with the remaining $100 \mathrm{~m}$ located in a field with an insect-pollinated crop

150 (e.g. clover) if present in the crop rotation, or if not, also in a field margin. Data from these

$151100 \mathrm{~m}$ section located in the field were not included in the analyses. Transects were divided

152 into shorter sections differentiated by crop types. The sections were marked on a map (scale

153 1:5000). During each fieldwork session, flower cover was estimated on a scale of 0-3 per

154 whole $2 \mathrm{~m}$ wide transect section where: $0=$ no flowers suitable for bumblebees; $1=>0$ to $1 / 3$ 
155 of the area with flowers suitable for bumblebees; $2=1 / 3$ to $2 / 3$ with suitable flowers, $3=>2 / 3$

156 covered with suitable flowers (Marja et al., 2014). All flowering-plant species known to be

157 used by bumblebees for foraging were classified as suitable (Table S2, Supporting

158 Information).

159 The bumblebee counts were conducted between 11:00 and 16:00 under good weather

160 conditions (temperature always above $15^{\circ} \mathrm{C}$, and no rain or strong wind). We mainly

161 identified bumblebees on flowers to species in the field. If identification on flowers was

162 impossible, individuals were caught, identified, and released in the field, or on very rare

163 occasions were retained to identify later in the laboratory. Each year the number of each

164 bumblebee species was summed per transect over the three counts.

165 To test our hypotheses we included only bumblebees, flower cover, and crop rotation

166 data of such transect sections which were located in the two most common types of field

167 margins, those alongside cereals and mass-flowering crops. Cereal fields included rye, oat,

168 barley, triticale, and wheat (hereafter cereals). The mass-flowering crop fields contained

169 legumes (pea, bean, clover, alfalfa, sweet clover spp.) and oilseed rape (hereafter MFC). Crop

170 harvest time depends on the crop and weather conditions and varies from June to September.

171 Legumes are typically harvested in June (first cut) and August (second cut), but sometimes

172 cut only once in July. Winter oilseed-rape is harvested at the end of July or in August, spring

173 oilseed-rape in September, cereals typically in August or at the beginning of September

174 (depending also if it is sown in autumn or in spring). The overall sample to test our

175 hypotheses comprised 401 transect sections, whose lengths varied between 40-500 m (mean

$176226 \pm$ SEM $6 \mathrm{~m}$ ). Sample size for each year (number of transect sections) were as follows:

177 2010: 80; 2011:78; 2012: 73, 2013: 84 and in 2014: 86 transect sections (401 in total). A cross

178 table of sample size by crop rotation and management type is given in Table 1. All other crop 
179 rotation types, such as potato, short-term grassland, permanent grassland, and pasture were

180 excluded from the analysis.

181 Part of the bumblebee dataset, the explanatory variables management type and flower 182 cover (years 2010-2012), is already published in Marja et al. (2014). However, in this study

183 we used a more comprehensive bumblebee dataset (2010-2014) that also included crop

184 rotation types. We added management type and flower cover into the analyses, as these are

185 important drivers of bumblebee abundances (Marja et al., 2014). Moreover, the present study

186 investigated different bumblebee variables: abundance of bumblebees sub-divided by

187 functional groups (tongue-length, colony size, and habitat preference), and threat status.

\subsection{Statistical analysis}

190 We analysed flower cover and bumblebee variables using linear mixed-effects models in R ( R

191 Development Core Team, 2016). The 'Ime4' (Bates et al., 2016) package for R was used to

192 conduct all analyses. Bumblebee response variables modelled were species richness,

193 abundance of all bumblebee species, abundance of long-tongued species (three species:

194 Bombus distinguendus, B. hortorum, and B. subterraneus), abundance of short- and medium-

195 tongued species (all other species, hereafter short-tongued species), abundance of threatened

196 species, and abundance of non-threatened species. We analysed long-tongued bumblebees

197 separately due to their specific ecological niche, i.e. only these species can pollinate flowers

198 with deep corollas, such as red clover and field bean. Species classified as vulnerable

199 (hereafter threatened) in Europe under the recent IUCN list (Nieto et al., 2014) were: Bombus

200 confusus, B. distinguendus, B. hypnorum, and B. muscorum. We also modelled pooled

201 bumblebee abundances based on species' colony size (large, medium, and small) and main

202 habitat (open-land specialists, forest specialists, and generalists). We used these life-history

203 traits, because a recent study indicated that bumblebees have trait-dependent vulnerability 
204 based on landscape heterogeneity (Persson et al., 2015). We provide a list of the bumblebee

205 species with classification according to tongue length, colony size, preferred habitat, and

206 threat status in Table S3, Supporting Information.

207 Owing to the bumblebees being over-dispersed, we used mixed-effects models with a 208 negative binomial distribution. The explanatory variables of main interest were crop rotation 209 type [four factors: cereal rollover fields (rollover = no change from one year to the next); 210 cereal to MFC fields; MFC rollover fields; MFC to cereal fields], (e.g. in cereal to MFC

211 fields, surveying was done in MFC field margin), management type (three levels:

212 conventional; environmentally friendly management; organic farming), and flower cover

213 (average value over the three counts per transect). Note that bumblebee response variables

214 were always taken during the second year of crop rotation. First, we tested flower cover as a

215 dependent variable in relation to crop rotation and management. Second, we tested all

216 bumblebee variables against crop rotation, management, and flower cover. Since we had

217 multiple years and the study regions had different landscape structures (Northern Estonia has

218 a simpler landscape structure than Southern Estonia), we treated year and region as crossed

219 random factors in the model (R command: (1|year)+(1|region). As the length of transect

220 sections ranged from 40 to $500 \mathrm{~m}$, they were treated as an offset function [R command:

221 offset $=\log ($ transect length) $]$. We also calculated the variance inflation factor between

222 explanatory variables (R package "car", Fox \& Weisberg, 2011), and identified no values

223 exceeding 1.4 for any of the models, which suggests that no collinearity occurred.

\section{3. Results}

226 We observed a total of 6092 individuals of 20 bumblebee species during 2010-2014 (see

227 Table S3, Supporting Information). We provide mean values and standard errors of 
investigated flower cover and bumblebee variables per transect sections length according to crop rotation and management type in Tables S4 and S5, Supporting Information.

Flower cover was higher in organic and environmentally friendly managed field margins, compared to the margins of conventional fields, but was not related with crop rotation types (Fig. 1). As an explanatory variable, flower cover was positively associated with all bumblebee groups (Fig. 2,3,4 and Fig. S3,S4).

Crop rotation type was not related to bumblebee species richness or abundance (Fig. S3, Supporting Information). Bumblebee species richness in the field margins of both AES management types were higher compared to the margins of conventional fields. Bumblebee abundance was significantly higher in environmentally friendly managed field margins compared to those of conventional fields; no significant difference in bumblebee abundance occurred between the field margins of organic and conventionally managed fields.

Abundances of non-threatened species did not differ between crop rotation types, but abundance of threatened species was highest in cereal rollover field margins, compared to the other three rotation types (Fig. 2). Bumblebee abundance of non-threatened species was significantly higher in environmentally friendly managed field margins compared to those of conventional field margins. Abundances of threatened species were higher in both AES management types field margins, compared to the margins of conventional fields.

Crop rotation type was associated with abundances of bumblebees of medium colony sizes (Fig. 3). Abundance of medium colony sized species was higher in cereal rollover field margins, compared to MFC rollover filed margins. Both AES management types had higher abundances of small-sized colony species.

Abundance of open land bumblebee species did not differ between crop rotation types. Abundance of generalist species was higher in cereal rollover field margins, compared to cereal to MFC and MFC rollover field margins (Fig. 4). Abundance of forest-scrub species 
253 was higher in cereal rollover field margins compared to MFC to cereal and MFC rollover

254 field margins. Abundances of open land species and generalists did not differ between field

255 margins under AES and conventional farming. Organic field margins hosted a higher

256 abundance of forest-scrub species compared to the margins of conventional fields.

257 Abundances of short-tongued species were similar in all investigated crop rotation types

258 (Fig. S4, Supporting Information). Abundance of long-tongued species was higher in cereal

259 rollover field margins compared to the other three crop rotation types. Bumblebee abundance

260 of short-tongued species was significantly higher in environmentally friendly managed field

261 margins compared to those of conventional field margins. Abundances of long-tongued

262 bumblebee species did not differ between management types.

263

\section{4. Discussion}

265 Our study shows that crop rotation has an important role in determining bumblebee

266 community. We found that some bumblebee abundances (e.g. of long-tongued and threatened

267 species) are higher at cereal rollover field margins than at the field margins of the other three

268 crop rotation types. Furthermore, we found higher abundances of medium sized colony

269 species, forest-scrub species, and habitat generalists in cereal rollover field margins than in

270 MFC rollover and MFC to cereal or cereal to MFC field margins.

272 4.1. Concentration and dilution effects of bumblebees at field margins

273 Our study suggests that crop rotation type is an important management driver of bumblebee

274 communities in field margins. Abundances of several bumblebee groups (e.g. long-tongued,

275 threatened, and forest-scrub species) were higher at the field margins of cereal rollover

276 compared to MFC rollover. This may not indicate that the status quo of fields remaining as 
277 cereals from one year to the next has a positive effect on bumblebee abundance, or that cereal

278 margins are more important to bumblebees than MFC margins.

279 Our results can be interpreted in two ways. First, this might have been caused by a

280 concentration effect in cereal field margins, similar to that found in Environmental

281 Stewardship AES in England (Carvell et al., 2007). More flower resources are available in the

282 margins of cereal fields than inside the fields, owing to herbicide use controlling arable weeds

283 within crops, thus reducing nectar sources (Brittain et al., 2010). Second, a dilution effect in

284 MFC fields (Holzschuh et al., 2011) is likely as bumblebees may disperse into MFC fields, as

285 they have more nectar resources than cereal fields. June and July, when $2 / 3$ of our data were

286 collected, is the main blooming time of legumes and oilseed rape in Estonia. Therefore,

287 dilution of bumblebee individuals from certain trait based groups onto MFC fields was

288 probably the main reason for the differences in bumblebee abundances between cereal and

289 MFC rollover field margins. One limitation of our investigation was that it only accounted for

290 bumblebees at field margins, not within fields. An important potential confounding factor that

291 needs to be mentioned vis-à-vie the concentration-dilution hypothesis of bumblebees (and

292 other pollinators) in cereal/MFC/other field margins, is the type of crop(s) being grown in

293 adjacent fields. For example, is there a stronger concentration effect if cereal fields are on

294 both sides of the field margin, than if the margin is between a cereal and MFC field? We

295 suggest that future studies test the concentration-dilution hypothesis by: $i$ ) also running

296 flower/pollinator transects from the edge to the centre of fields; ii) taking into account

297 adjacent fields.

298 Our results suggest a negative temporal effect of cereal fields upon the food resources

299 of bumblebees. Abundances of threatened, long-tongued, and forest-scrub species were lower

300 in the field margins of MFC to cereal than cereal rollover fields. We offer the following

301 explanation: if cereals are grown for two consecutive years, this may already negatively 
302 influence the flowering plant community of the field, reducing food resources for bumblebees

303 within fields, thus making margins more attractive to bumblebees. In addition, as cereal

304 rollover fields were mainly on conventional farms (Table 1), such field margins are less likely

305 to: $i$ ) have MFC dispersal into the margin from the previous year; $i i$ ) be managed (including

306 the sowing of seed mixes) for wildflowers. From a recent study (Magrach et al., 2017) it is

307 known that honeybees spillover from mass-flowering orange groves to flower-rich woodlands

308 after orange bloom leading to a change in wild bee community composition and lower seed

309 set of the most common plant species. Nevertheless, for the honeybee itself this might be a

310 benefit. In a similar way, it is possible that for at least some bumblebee species, MFC can

311 provide a benefit the following year, as suggested by our results (MFC $>$ cereal compared to

312 cereal rollover).

313 The importance of field margins is related to nectar and/or pollen continuity in agricultural

314 landscapes (Schellhorn, Gagic \& Bommarco, 2015). Owing to the seasonality and duration of

315 nectar sources, legumes and oilseed rape fields are not fully available to bees throughout

316 spring and summer in Northern Europe, thus bumblebees likely also use semi-natural habitats,

317 such as field margins (Bäckman \& Tiainen, 2002; Batáry et al., 2015). Therefore, flowering

318 field margins are of high importance during periods when legumes or oilseed rape resources

319 are not available, thus creating a resource bottleneck (Persson et al., 2015; Schellhorn, Gagic

$320 \&$ Bommarco, 2015). In our study areas, a resource bottleneck might occur if MFC are not

321 grown in certain years, do not flower until a certain date, or are harvested from a certain date

322 onwards. Thus, it is highly likely that a combination of all three presented reasons affects the

323 availability of food resources for bumblebees.

324

325

4.2. AES has a role in determining the bumblebee communities of field margins 
326 We found that both organic farming and environmentally friendly management promoted

327 bumblebee species richness in field margins. It might be possible that farming practice had a

328 confounding effect on the results, e.g. conventional farms had a higher percentage of cereal

329 rollover fields compared to organic and environmentally friendly management farms, but

330 owing to the lack of collinearity, a significant bias seems to be unlikely. Nonetheless, future

331 studies should aim to collect more balanced datasets. However, Marja et al. (2014), also

332 demonstrated that Estonian AES promoted bumblebees, both within the fields and at their

333 margins. Environmentally friendly management involves requirements to conserve or sow

334 field margins with a flower mix of at least three species (including graminaceous); organic

335 farming does not have such a requirement, but abundances of bumblebee threatened species,

336 small-sized colony species, and forest-scrub species were still higher than per conventional

337 farming. This was probably related to the strict management requirements (synthetic

338 pesticides and most mineral fertilizers are forbidden) of organic farming. Our results indicate

339 that threatened species are remarkably sensitive to agricultural management, and prefer more

340 AES, farms; non-threatened species seemed to be less sensitive to management.

341 We found that the abundances of species with small colonies were related to AES

342 management types, whereas abundances of species with medium and large colonies did not

343 differ between management types. These results can be related to the mobility potential.

344 Species with small colonies have more limited dispersal distances (Westphal, Steffan-

345 Dewenter \& Tscharntke, 2006). This adaptation makes them more sensitive to local

346 environmental and agricultural conditions. It is also probable that there were more suitable

347 habitat conditions in organic and environmentally friendly management field margins for

348 bumblebee species with small colonies. Species with medium and large colonies are more

349 mobile and search for resources at larger scales, and are therefore less influenced by local

350 conditions. 
352

353

354

355

356

357

358

359

360

361

362

363

364

365

366

367

368

369

370

371

372

373

374

375

\subsection{Conservation of bumblebees}

Both naturally-occurring plants and the sowing of seed mixes to provide nectar-rich plants (e.g. clover) at field margins can benefit bumblebees and other pollinators in Estonia as well as in Northern Europe in general (Scheper et al., 2013). It is important when sowing nectarrich plants mixes, to use only local flora to avoid introducing alien species. The conservation of non-cropped landscape elements, such as field margins and other flower resources, is essential to support the diversity of wild pollinators and their food plants. For instance, the latest results from Estonia showed that field margins need to be at least $3 \mathrm{~m}$ wide to support 'high nature value' plant species intolerant of modern farming practices (Aavik \& Liira, 2010). For bumblebees, these plant species are potentially of higher value and provide more temporally stable food resources than agro-tolerant plant species. Thus, non-cropped field margins at least 3-5 $\mathrm{m}$ wide could be a key and simple solution to improve bumblebee diversity in cereal-dominated agricultural landscapes. Furthermore, permanent field margins are important for bumblebees in terms of the continuity of resources other than food, such as nesting and wintering habitat (Bäckman \& Tiainen, 2002; Batáry et al., 2015).

A recent study showed that almost $80 \%$ of crop pollination is performed by a limited number of bee species, and threatened bee species contribute little (Kleijn et al., 2015). However, protecting the main, common pollinator species only is not a sustainable solution to the conservation of pollinator biodiversity. Senapathi et al. (2015) highlighted that maintaining whole pollinator species diversity, including widespread and rare species, is essential to provide ecosystem resilience and functioning in the future. Therefore, the conservation of different habitats and the whole pollinator species spectrum is crucial, because different pollinator species visit different parts of crops, or crops at different times of the day or year, and respond differently to environmental disturbances (Goulson et al., 2015). 


\section{Conclusions}

378 Our results indicate that cereal field margins can act as refugia to forest-scrub, long-tongued, and threatened bumblebee species, such as B. hypnorum, B. distinguendus, and B. muscorum, which are vulnerable in Europe (Nieto et al., 2014). Semi-natural field margins, especially in intensively managed cropland, may be a viable option to support these species in Europe, because they represent permanent valuable landscape elements, offering places to nest and overwinter, as well as providing food resources. It is possible that the field margin requirement of Estonian AES is one of the reasons why Estonian bumblebee abundances were stable over a recent five year period (Agriculture Research Centre, 2015). Our study indicated a concentration-dilution effect of field margins upon bumblebee abundances, dependant on the type of crop being grown in the field (cereal = concentration at the margin; $\mathrm{MFC}=$ dilution into the field). To test the concentration-dilution hypothesis of field margins upon pollinators, future studies should account for within-field pollinator/flower abundances, and the influence of adjacent fields (or even landscape composition). Nonetheless, our results

391 show that management of flower rich field margins, especially in cereal rollover fields, where

392 few alternative nectar sources exist, is important and should form part of all AES targeting 393 pollinators.

\section{Acknowledgements}

396 The census work was coordinated by the Agricultural Research Centre as part of the ongoing

397 evaluation of AES within the framework of the Estonian Rural Development Plan 2007-2013,

398 financed by the European Union and Estonian government under the Technical Assistance measure of the 2007-2013 Rural Development Plan of Estonia. M.M. research was partly 
401 Education. P.B. was supported by the German Research Foundation (DFG BA4438/2-1) and

402 by the Economic Development and Innovation Operational Programme of Hungary (GINOP-

403 2.3.2-15-2016-00019). The authors are thankful to Katrin Jõgar, Martin Jürgenson, Reet

404 Karise, Irja Kivimägi, Eha Kruus, Reelika Päädam, Eve Veromann, Kai-Riin Veromann,

405 Linda-Liisa Veromann-Jürgenson, and Peeter Veromann for their help in conducting the

406 fieldwork.

407

408 Authors' Contributions

409 RM and PB conceived the study and designed the methodology; EV and MM coordinated

410 data collection; RM analysed the data; RM led the writing of the manuscript. All authors

411 (RM, EV, MM, JP, AMK, and PB) contributed critically to the manuscript and approved the

412 submission.

413

414 Data accessibility

415 Data availability. The biodiversity and environmental data used in the analyses are archived at

416 the research data repository Zenodo (https://zenodo.org/record/1161431).

417 


\section{$418 \quad$ References}

419 Aavik, T., \& Liira, J. (2010) Quantifying the effect of organic farming, field boundary type 420 and landscape structure on the vegetation of field boundaries. Agriculture, Ecosystems and Environment, 135, 178-186.

422

423

424

425

426

427

428

429

430

432

433

434

435

436

437

438

440

441

Agricultural Research Centre. (2015) Estonian Rural Development Plan 2007-2013 annual report of axis 2 ongoing evaluation activities in 2014. Saku, Estonia. (in Estonian).

Bäckman, J.-P. C., \& Tiainen, J. (2002) Habitat quality of field margins in a Finnish farmland area of bumblebees (Hymenoptera: Bombus and Psithyrus). Agriculture, Ecosystems \& Environment, 89, 53-68.

Batáry, P., Dicks, L.V., Kleijn, D., \& Sutherland, W.J. (2015) The role of agri-environment schemes in conservation and environmental management. Conservation Biology, 29, 1006-1016.

Bates, D., Maechler M., Bolker, B., Walker, S., Bojesen, R.H.C.,Singmann, H., ... Green, P. (2016) Package lme4: Linear Mixed-Effects Models using 'Eigen' and S4. URL: https://cran.r-project.org/web/packages/lme4/lme4.pdf

Blüthgen, N., \& Klein, A.-M. (2011) Functional complementarity and specialisation: the role of biodiversity in plant-pollinator interactions. Basic and Applied Ecology, 12, 282291.

Bommarco, R., Lundin, O., Smith, H.G., \& Rundlöf, M. (2012) Drastic historic shifts in bumble-bee community composition in Sweden. Proceedings of the Royal Society of London B, 279, 309-315.

Brittain, C.A., Vighi, M., Bommarco, R., Settele, J., \& Potts, S.G. (2010) Impacts of a pesticide on pollinator species richness at different spatial scales. Basic and Applied Ecology, 11, 106-115. 
442 Carvell, C., Meek, W.R., Pywell, R.F., Goulson, D., \& Nowakowski, M. (2007) Comparing

443 the efficacy of agri-environment schemes to enhance bumble bee abundance and

444 diversity on arable field margins. Journal of Applied Ecology, 44, 29-40.

445 Carvell, C., Bourke, A.F.G., Osborne, J.L., \& Heard, M.S. (2015) Effects of an agri-

446 environment scheme on bumblebee reproduction at local and landscape scales. Basic

447 and Applied Ecology, 16, 519-530.

448 Fox, J., \& Weisberg, S. (2011) Companion to Applied Regression, Second Edition. Thousand

449 Oaks CA: Sage. URL: http://socserv.socsci.mcmaster.ca/jfox/Books/Companion.

450 Goulson, D. (2010) Bumblebees. Behaviour, ecology and conservation. Second edition.

$451 \quad$ Oxford University Press.

452 Goulson, D., Lye, G.C. \& Darvill, B. (2008) Decline and conservation of bumble bees.

453 Annual Review of Entomology, 53, 191-208.

454 Goulson, D., Nicholls, E., Botias, C., \& Rotheray, E. (2015) Bee declines driven by combined

455 stress from parasites, pesticides, and lack of flowers. Science, 347, 1435-1443.

456 Hole, D.G., Perkins, A.J., Wilson, J.D., Alexander, I.H., Grice, F., \& Evans, A.D. (2005)

457 Does organic farming benefit biodiversity? Biological Conservation, 122, 113-130.

458 Holzschuh, A., Dormann, C.F., Tscharntke, T., \& Steffan-Dewenter, I. (2011) Expansion of

459 mass-flowering crops leads to transient pollinator dilution and reduced wild plant

$460 \quad$ pollination. Proceedings of the Royal Society of London B, 278, 3444-3451.

461 IPBES. (2016) Summary for policymakers of the assessment report of the Intergovernmental

462 Science-Policy Platform on Biodiversity and Ecosystem Services on pollinators,

$463 \quad$ pollination and food production.

464 Klein, A.-M., Vaissiere, B., Cane, J.H., Steffan-Dewenter, I., Cunningham, S.A., Kremen, C.,

465 \& Tscharntke, T. (2007) Importance of crop pollinators in changing landscapes for

$466 \quad$ world crops. Proceedings of the Royal Society of London B, 274, 303-313. 
467 Kleijn, D., Rundlöf, M., Scheper, J., Smith, H.G., \& Tscharntke, T. (2011) Does conservation 468 on farmland contribute to halting the biodiversity decline? Trends in Ecology and 469 Evolution, 26, 474-481.

470 Kleijn, D., Winfree, R., Bartomeus, I., Carvalheiro, L.G., Henry, M., Isaacs, R.,... Potts, S.G. 471 (2015) Delivery of crop pollination services is an insufficient argument for wild 472 pollinator conservation. Nature Communications, 6, 7414.

Kremen, C., Williams, N.M., Aizen, M.A., Gemmill-Herren, B., LeBuhn, G., Minckley, R., ... Ricketts, T.H. (2007) Pollination and other ecosystem services produced by mobile organisms: a conceptual framework for the effects of land-use change. Ecology Letters,

Magrach, A., González-Varo, J.P., Boiffier, M., Vilà, M., \& Bartomeus, I. (2017) Honeybee spillover reshuffles pollinator diets and affects plant reproductive success. Nature

Marja, R., Herzon, I., Viik, E., Elts, J., Mänd, M., Tscharntke, T., \& Batáry, P. (2014) Environmentally friendly management as an intermediate strategy between organic and conventional agriculture to support biodiversity. Biological Conservation, 178, 146154.

Nieto, A., Roberts, S.P.M., Kemp, J., Rasmont, P., Kuhlmann, M., García Criado, M., ... Miches, D. (2014) European Red List of bees. Luxembourg: Publication Office of the European Union.

Persson, A.S., Rundlöf, M., Clough, Y., \& Smith, H.G. (2015) Bumble bees show traitdependent vulnerability to landscape simplification. Biodiversity and Conservation, 24, $3469-3489$. 
490

491

492

493

494

495

496

497

498

499

500

501

502

503

504

505

506

507

508

509

510

511

512

513

Potts, S.G., Biesmeijer, J.C., Kremen, C., Neumann, P., Schweiger, O., \& Kunin, W.E. (2010) Global pollinator declines: trends, impacts and drivers. Trends in Ecology and Evolution, 25, 345-353.

Potts, S.G., Imperatriz-Fonseca, V., Ngo, H.T., Aizen, M.A., Biesmeijer, J.C., Breeze, T.D., \& Vanbergen, A.J. (2016). Safeguarding pollinators and their values to human wellbeing. Nature, 540, 220-229.

R Development Core Team. (2016) R: A language and environment for statistical computing. R Foundation for Statistical Computing, Vienna, Austria. ISBN 3-900051-07-0, URL: http://www.R-project.org

Schellhorn, N.A., Gagic, V., \& Bommarco, R. (2015) Time will tell: resource continuity bolsters ecosystem services. Trends in Ecology and Evolution, 30, 524-530.

Scheper, J., Holzschuh, A., Kuussaari, M., Potts, S.G., Rundlöf, M., Smith, H.G., \& Kleijn, D. (2013) Environmental factors driving the effectiveness of European agri-environmental measures in mitigating pollinator loss - a meta-analysis. Ecology Letters, 16, 912-920

Senapathi, D., Biesmeijer, J.C., Breeze, T.D., Kleijn, D., Potts, S.G., \& Carvalheiro, L.G. (2015) Pollinator conservation - the difference between managing for pollination services and preserving pollinator diversity. Current Opinion in Insect Science, 12, $93-$ 101.

Sutcliffe, L., Batáry, P., Kormann, U., Báldi, A., Dicks, L., Herzon, I., ... Tscharntke, T. (2015) Harnessing the biodiversity value of Central and Eastern European farmland. Diversity and Distributions, 21, 722-730.

Tscharntke, T., Klein, A.-M., Kruess, A., Steffan-Dewenter, I., \& Thies, C. (2005) Landscape perspectives on agricultural intensification and biodiversity-ecosystem service management. Ecology Letters, 8, 857-874. 
514 Tscharntke, T., Tylianaskis, J.M., Rand, T.A., Didham, R.K., Fahrig, L., Batáry, P., ...

515 Westphal, C. (2012) Landscape moderation of biodiversity patterns and processes-eight

516 hypotheses. Biological Reviews, 87, 661-685.

517 Westphal, C., Steffan-Dewenter, I., \& Tscharntke, T. (2003) Mass flowering crops enhance

518 pollinator densities at a landscape scale. Ecology Letters, 11, 961-965.

519 Westphal, C., Steffan-Dewenter, I., \& Tscharntke, T. (2006) Bumblebees experience

520 landscapes at different spatial scales: possible implications for coexistence. Oecologia,

$521 \quad \mathbf{1 4 9}, 289-300$.

522 Williams, N.M., Ward, K.L., Pope, N., Isaacs, R., Wilson, J. \& May, E.A., ... Peters, J.

523 (2015) Native wildflower plantings support wild bee abundance and diversity in

524 agricultural landscapes across the United States. Ecological Applications, 25, 2119-

2131.

526 Williams, P.H., \& Osborne J.L. (2009) Bumblebee vulnerability and conservation world-

$527 \quad$ wide. Apidologie, 40, 367-387.

528 Winfree, R., Aguilar, R., Vazquez, D.P., LeBuhn, G., \& Aizen, M.A. (2009) A meta-analysis

529 of bees' responses to anthropogenic disturbance. Ecology, 90, 2068-2076.

530 Wood, T.J., Holland, J.M., \& Goulson, D. (2015) A comparison of techniques for assessing

531 farmland bumblebee populations. Oecologia, 177, 1093-1102.

532 Wood, T.J., Holland, J.M., Hughes, W.O.H., \& Goulson, D. (2015) Targeted agri-

533 environment schemes significantly improve the population size of common farmland

$534 \quad$ bumblebee species. Molecular Ecology, 24, 1668-1680. 


\section{Table captions}

536

537 Table 1 Cross-table of sample sizes by crop rotation and management types. Cereal (all rye,

538 oat, barley, triticale, and wheat fields), MFC = mass-flowering crops (pea, bean, clover,

539 alfalfa, sweet clover species, and oilseed rape).

\begin{tabular}{lcccc}
\hline $\begin{array}{l}\text { Management type/ } \\
\text { Crop rotation }\end{array}$ & $\begin{array}{l}\text { Conventional } \\
\text { farming }\end{array}$ & $\begin{array}{l}\text { Environmentally } \\
\text { friendly management }\end{array}$ & $\begin{array}{l}\text { Organic } \\
\text { farming }\end{array}$ & $\begin{array}{l}\text { Crop rotation } \\
\text { total }\end{array}$ \\
\hline Cereal $\rightarrow$ cereal & 86 & 22 & 9 & 117 \\
Cereal $\rightarrow$ MFC & 17 & 46 & 24 & 87 \\
MFC $\rightarrow$ cereal & 28 & 36 & 19 & 83 \\
MFC $\rightarrow$ MFC & 17 & 31 & 66 & 114 \\
Management type total & 148 & 135 & 118 & 401 \\
\hline
\end{tabular}

540

541

542 


\section{$543 \quad$ Figure captions}

544 Fig. 1. Comparison of flower cover in field margins between different crop rotation and

545 management types. The figure shows results from linear mixed-effects models ( $\mathrm{p}$-value, lower

546 and upper boundary of $95 \% \mathrm{CI}$ ). Indicated are effect sizes (y-axis) compared to the crop

547 rotation type control group (cereal rollover field margins) and management type control group

548 (conventional farming). The effect size is significantly different if the CIs do not overlap with

549 zero. Asterisk symbols represent statistically significant p-values below $0.05,0.01$, and 0.001

$550 \quad(*, * *$, and $* * *$, respectively). Cer = cereals (all rye, oat, barley, triticale, and wheat fields),

$551 \mathrm{MFC}=$ mass flowering crops (pea, bean, clover, alfalfa, sweet clover species, and oilseed

552 rape), Environmental $=$ environmentally friendly management, Organic $=$ organic farming. 553

554 
555 Fig. 2. Comparison of bumblebee abundances in field margins between different crop rotation 556 types, management types, and effect of flower cover for (a) non-threatened and (b) threatened 557 bumblebee species. The figure shows results from linear mixed-effects models (p-value, 558 lower and upper boundary of $95 \% \mathrm{CI}$ ). Indicated are effect sizes (y-axis) compared to the crop 559 rotation type control group (cereal rollover field margins) and management type control group 560 (conventional farming). The effect size is significantly different if the CIs do not overlap with 561 zero. Asterisk symbols represent statistically significant p-values below $0.05,0.01$, and 0.001

$562\left(*, * *\right.$, and ${ }^{* * *}$, respectively). Cer $=$ cereals (all rye, oat, barley, triticale, and wheat fields), $563 \mathrm{MFC}=$ mass flowering crops (pea, bean, clover, alfalfa, sweet clover species, and oilseed

564 rape), Environmental $=$ environmentally friendly management, Organic $=$ organic farming, 565 Flowers $=$ flower cover.

566

567 
568 Fig. 3. Comparison of bumblebee abundances in field margins between different crop rotation 569 types, management types, and effect of flower cover for species based on their colony size, 570 i.e. (a) large, (b) medium and (c) small colonies. The figure shows results from linear mixed571 effects models (p-value, lower and upper boundary of 95\% CI). Indicated are effect sizes (y572 axis) compared to the crop rotation type control group (cereal rollover field margins) and 573 management type control group (conventional farming). The effect size is significantly 574 different if the CIs do not overlap with zero. Asterisk symbols represent statistically 575 significant $\mathrm{p}$-values below $0.05,0.01$, and $0.001(* * *$ and, $* * *$, respectively). Cer $=$ cereals

576 (all rye, oat, barley, triticale, and wheat fields), MFC = mass flowering crops (pea, bean, 577 clover, alfalfa, sweet clover species, and oilseed rape), Environmental = environmentally 578 friendly management, Organic $=$ organic farming, Flowers $=$ flower cover. 579 
580 Fig. 4. Comparison of bumblebee abundances in field margins between different crop rotation

581 types, management types, and effect of flower cover for species based on their habitat

582 preference, i.e. (a) open land, (b) generalists, and (c) forest-scrub. The figure shows results

583 from linear mixed-effects models (p-value, lower and upper boundary of $95 \% \mathrm{CI}$ ). Indicated

584 are effect sizes (y-axis) compared to the crop rotation type control group (cereal rollover field

585 margins) and management type control group (conventional farming). The effect size is

586 significantly different if the CIs do not overlap with zero. Asterisk symbols represent

587 statistically significant $\mathrm{p}$-values below $0.05,0.01$, and $0.001(*, * *$ and, $* * *$ respectively). Cer

$588=$ cereals (all rye, oat, barley, triticale, and wheat fields), MFC = mass flowering crops (pea,

589 bean, clover, alfalfa, sweet clover species, and oilseed rape), Environmental =

590 environmentally friendly management, Organic $=$ organic farming, Flowers $=$ flower cover. 


\section{Supporting Information}

592

593 Table S1. Requirements of conventional farming and the two agri-environment schemes.

594

595

Table S2. Flowering plant species known to be used by bumblebees for foraging.

596

Table S3. Bumblebee species' traits based on tongue length, threat status, colony size and main habitat type.

599

600

Table S4. Investigated plant and bumblebee variables depending on crop rotation type (mean

601 values and standard error of mean).

602

603

Table S5. Investigated plant and bumblebee variables depending on management type (mean

604 values and standard error of mean).

605

606

Figure S1. Illustrative photos of field margins.

607

608

Figure S2. Study areas in the two regions of Northern and Southern Estonia.

609

610 Figure S3. Comparisons of bumblebee species richness and abundance in field margins

611 between different crop rotation types, management types, and effect of flower cover.

612

613 Figure S4. Comparisons of bumblebee abundance of short- and long-tongued bumblebee

614 species in field margins between different crop rotation types, management types, and effect 615 of flower cover. 


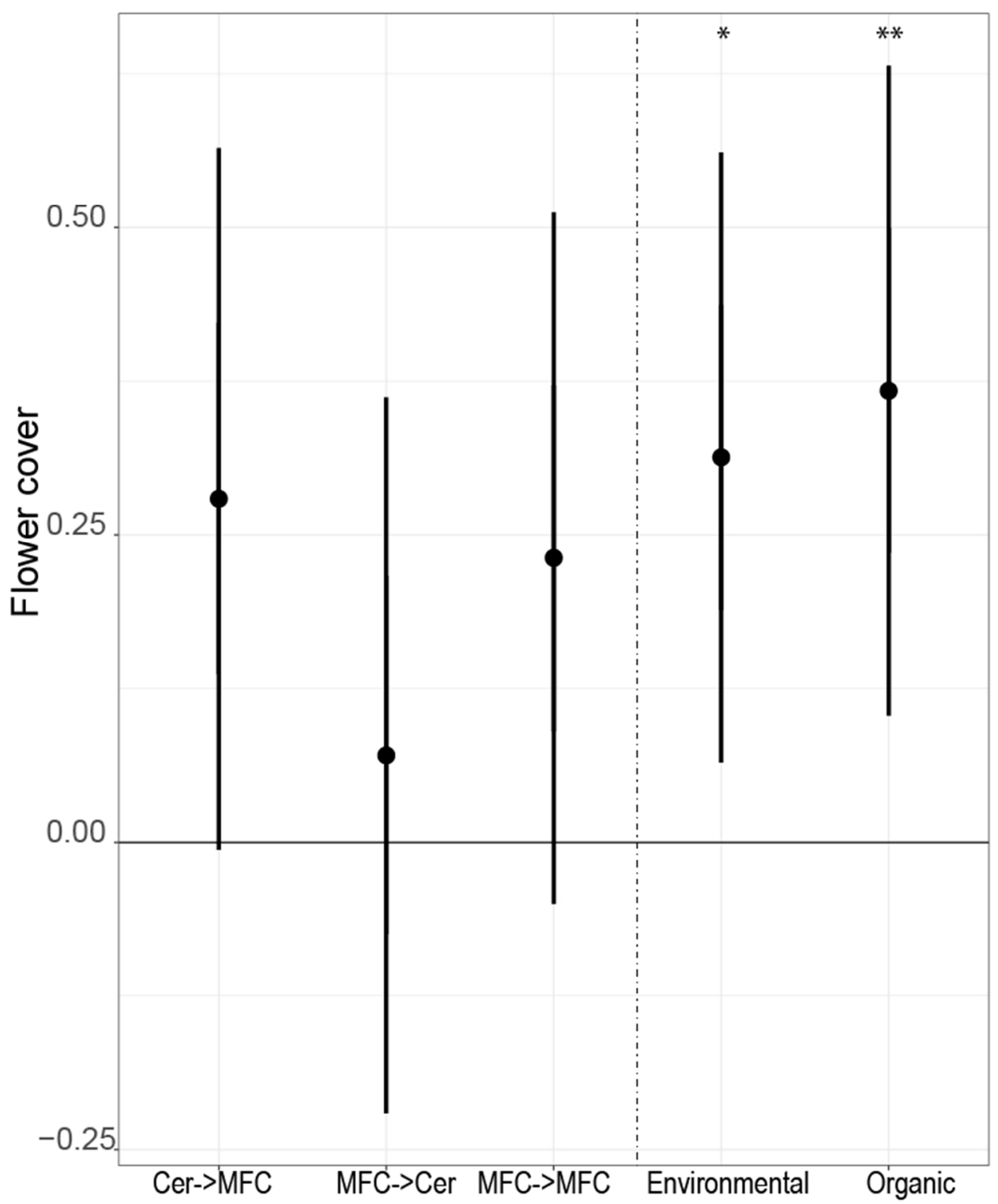

Fig. 1. Comparison of flower cover in field margins between different crop rotation and management types. The figure shows results from linear mixed-effects models ( $p$-value, lower and upper boundary of $95 \% \mathrm{CI}$ ). Indicated are effect sizes ( $y$-axis) compared to the crop rotation type control group (cereal rollover field margins) and management type control group (conventional farming). The effect size is significantly different if the CIs do not overlap with zero. Asterisk symbols represent statistically significant $p$-values below $0.05,0.01$, and $0.001(*, * *$, and $* * *$, respectively). Cer $=$ cereals (all rye, oat, barley, triticale, and wheat fields), MFC = mass flowering crops (pea, bean, clover, alfalfa, sweet clover species, and oilseed rape), Environmental = environmentally friendly management, Organic = organic farming. 


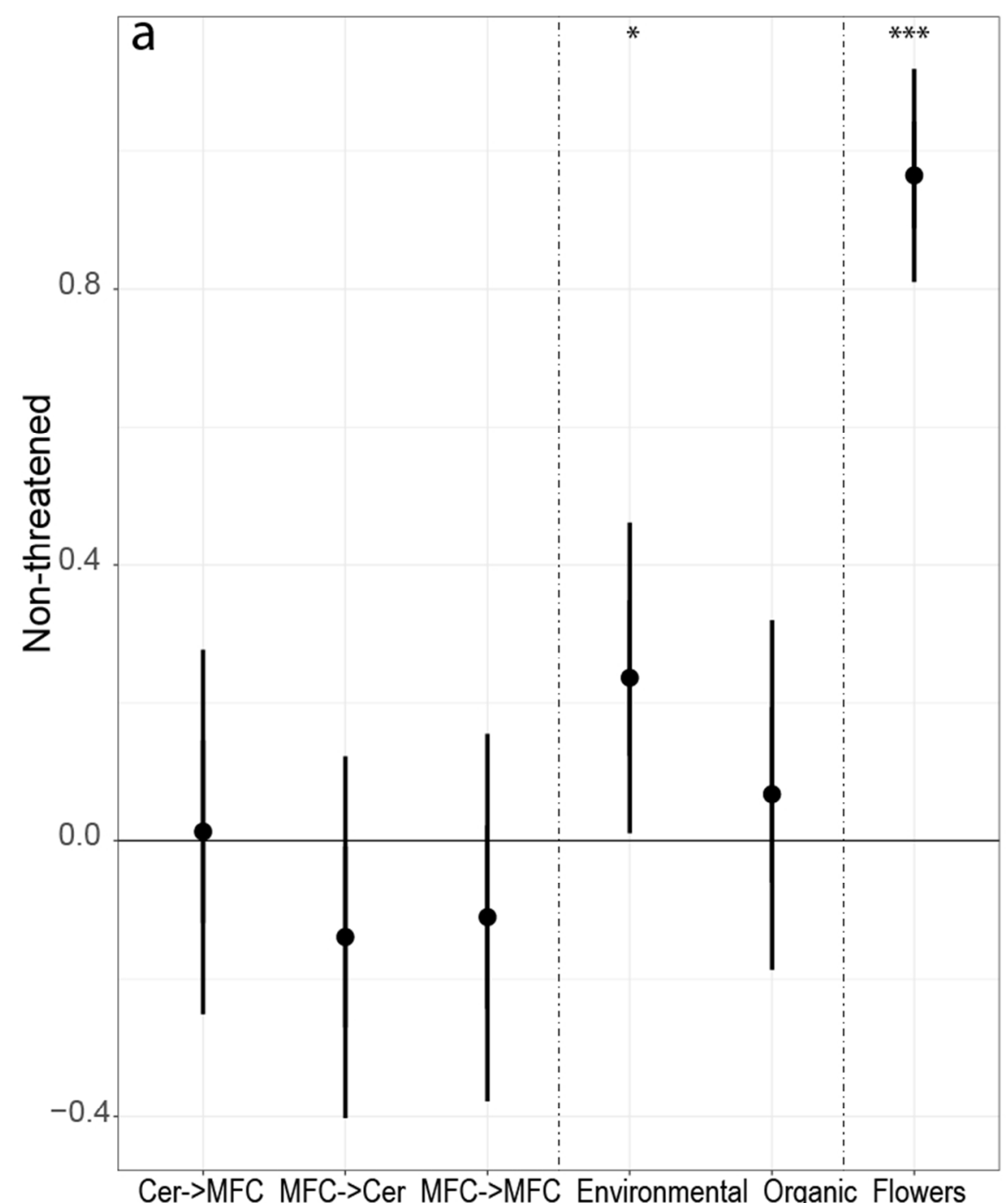

Fig. 2. Comparison of bumblebee abundances in field margins between different crop rotation types, management types, and effect of flower cover for (a) non-threatened and (b) threatened bumblebee species. The figure shows results from linear mixed-effects models ( $p$-value, lower and upper boundary of $95 \% \mathrm{CI}$ ). Indicated are effect sizes (y-axis) compared to the crop rotation type control group (cereal rollover field margins) and management type control group (conventional farming). The effect size is significantly different if the CIs do not overlap with zero. Asterisk symbols represent statistically significant $p$-values below $0.05,0.01$, and $0.001(*, * *$, and $* * *$, respectively). Cer = cereals (all rye, oat, barley, triticale, and wheat fields), MFC = mass flowering crops (pea, bean, clover, alfalfa, sweet clover species, and oilseed rape), Environmental $=$ environmentally friendly management, Organic $=$ organic farming, Flowers $=$ flower cover. 


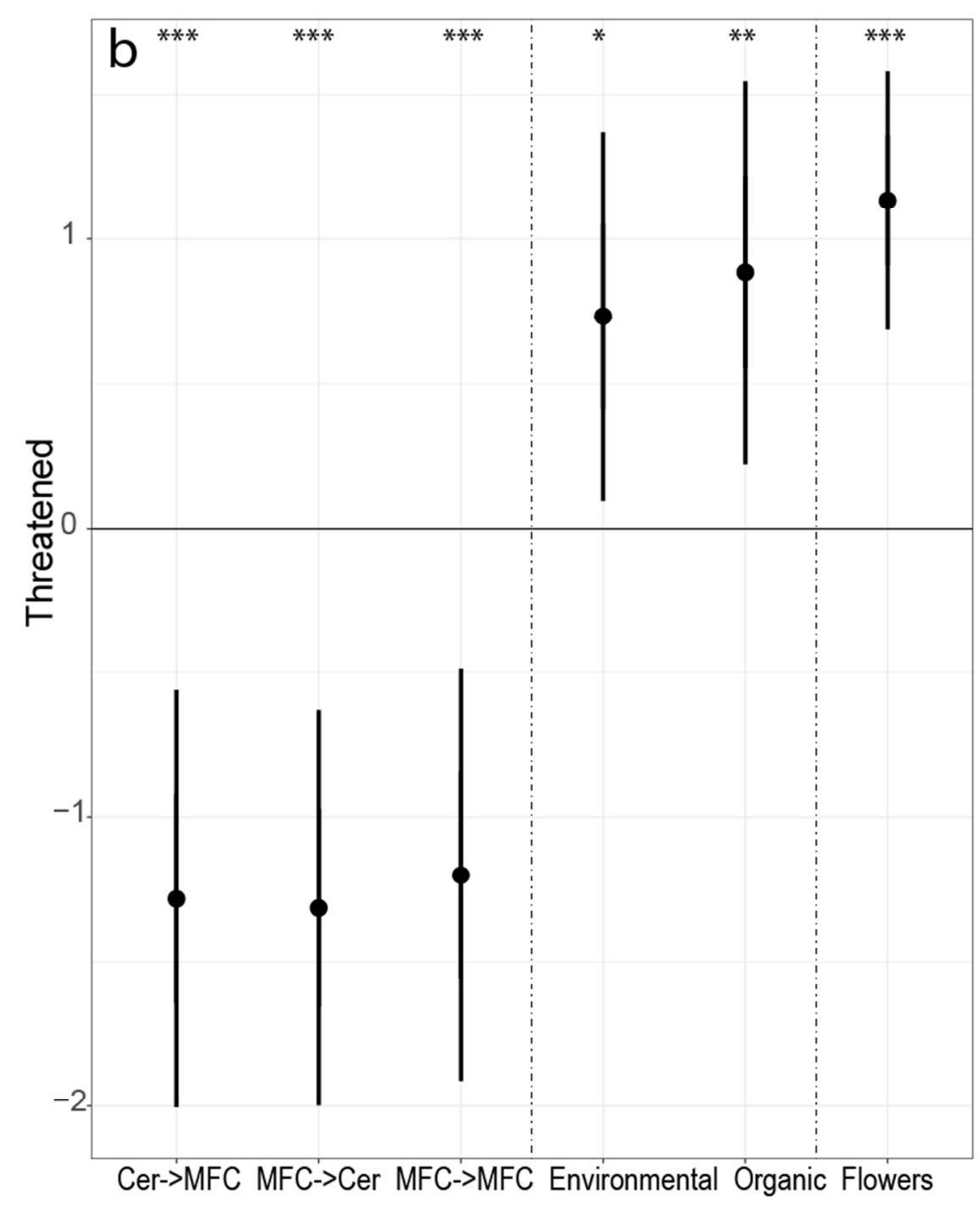

Figure $2 \mathrm{~B}$

$253 \times 279 \mathrm{~mm}(90 \times 90 \mathrm{DPI})$ 


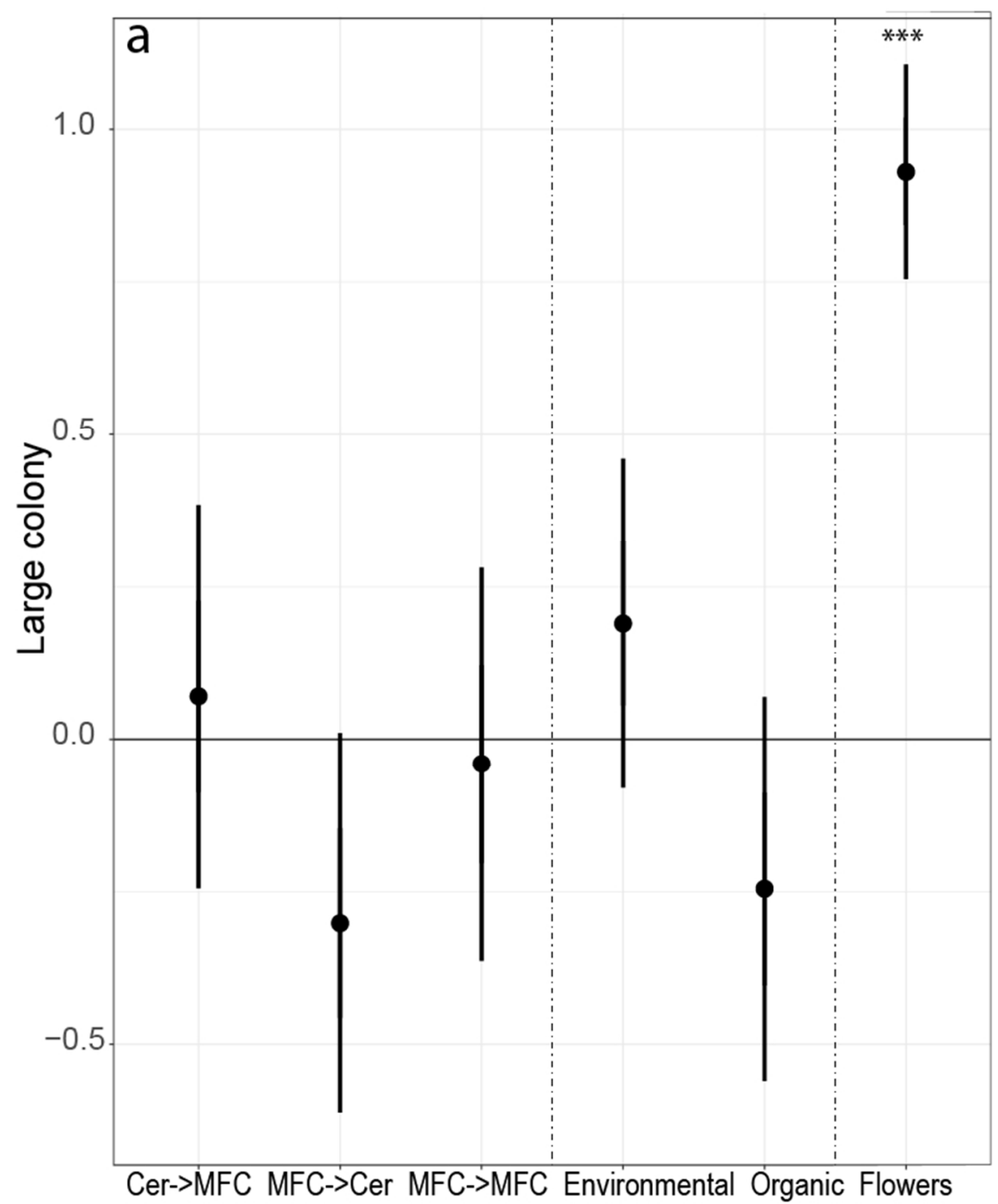

Fig. 3. Comparison of bumblebee abundances in field margins between different crop rotation types, management types, and effect of flower cover for species based on their colony size, i.e. (a) large, (b) medium and (c) small colonies. The figure shows results from linear mixed-effects models ( $p$-value, lower and upper boundary of $95 \% \mathrm{CI}$ ). Indicated are effect sizes ( $y$-axis) compared to the crop rotation type control group (cereal rollover field margins) and management type control group (conventional farming).

The effect size is significantly different if the CIs do not overlap with zero. Asterisk symbols represent statistically significant p-values below $0.05,0.01$, and $0.001(*, * *$ and, $* * *$, respectively). Cer $=$ cereals

(all rye, oat, barley, triticale, and wheat fields), MFC = mass flowering crops (pea, bean, clover, alfalfa, sweet clover species, and oilseed rape), Environmental = environmentally friendly management, Organic = organic farming, Flowers $=$ flower cover. 


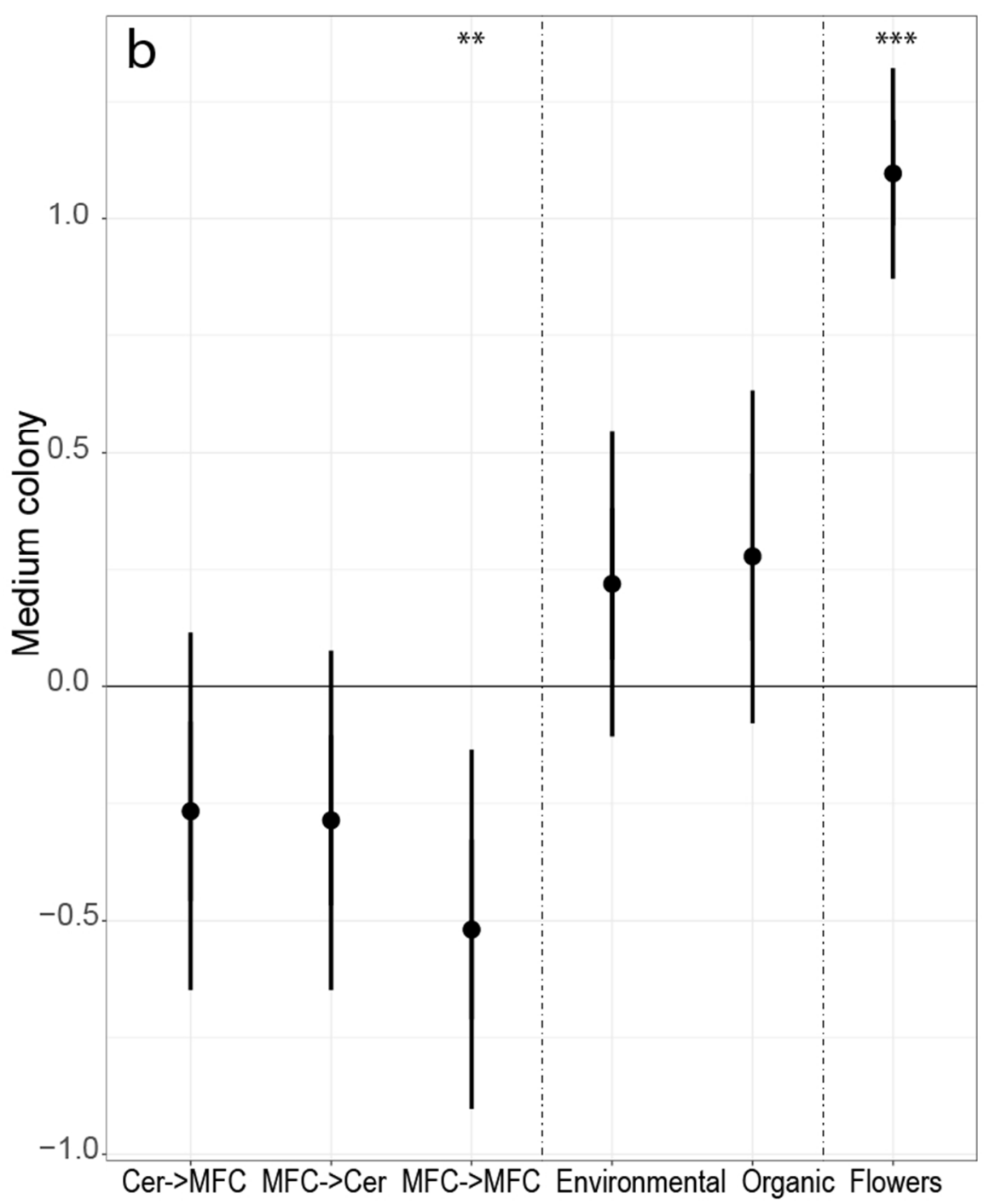

Figure $3 \mathrm{~b}$

$253 \times 279 \mathrm{~mm}(90 \times 90 \mathrm{DPI})$ 


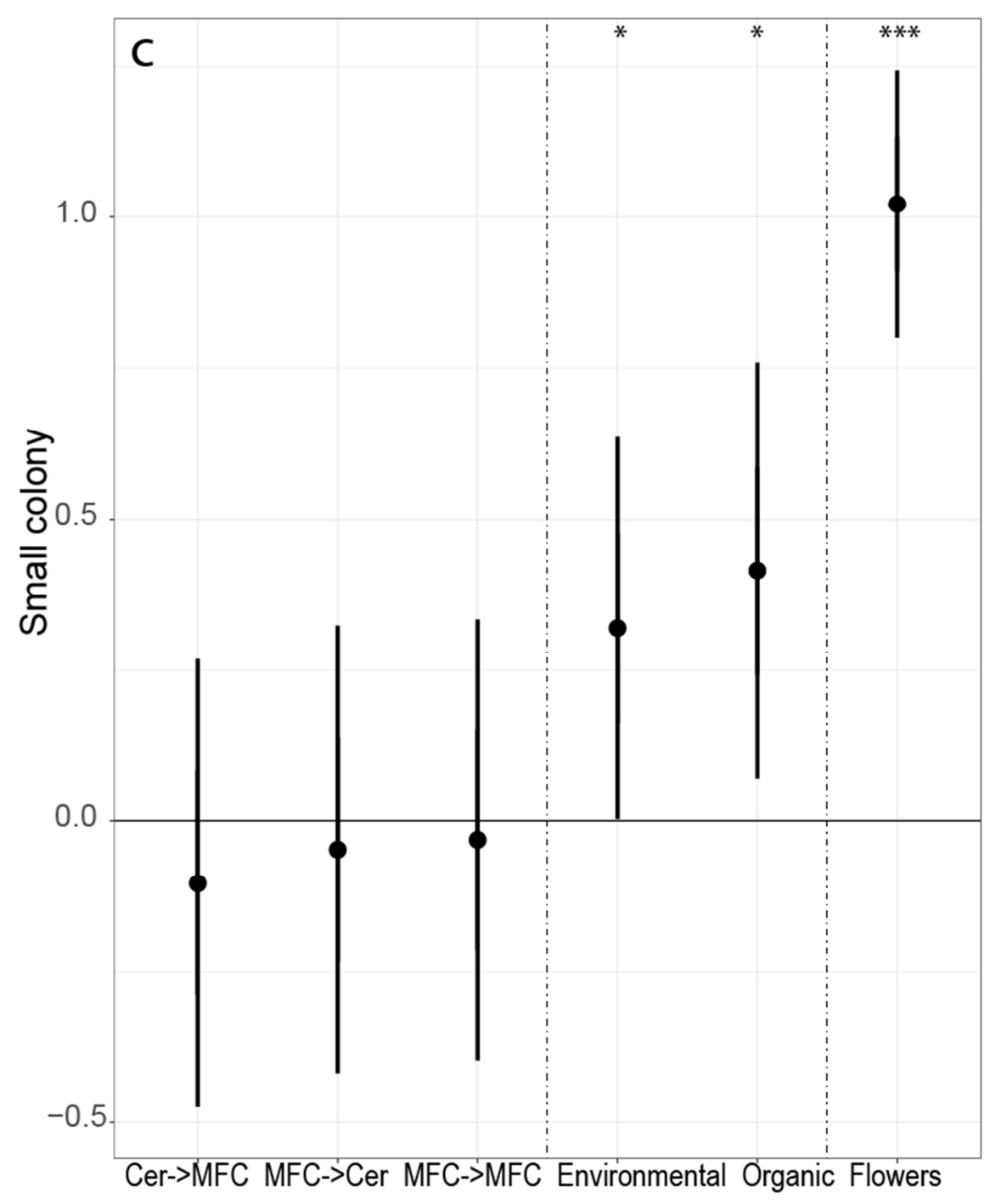

Figure $3 \mathrm{c}$

$253 \times 279 \mathrm{~mm}(90 \times 90 \mathrm{DPI})$ 


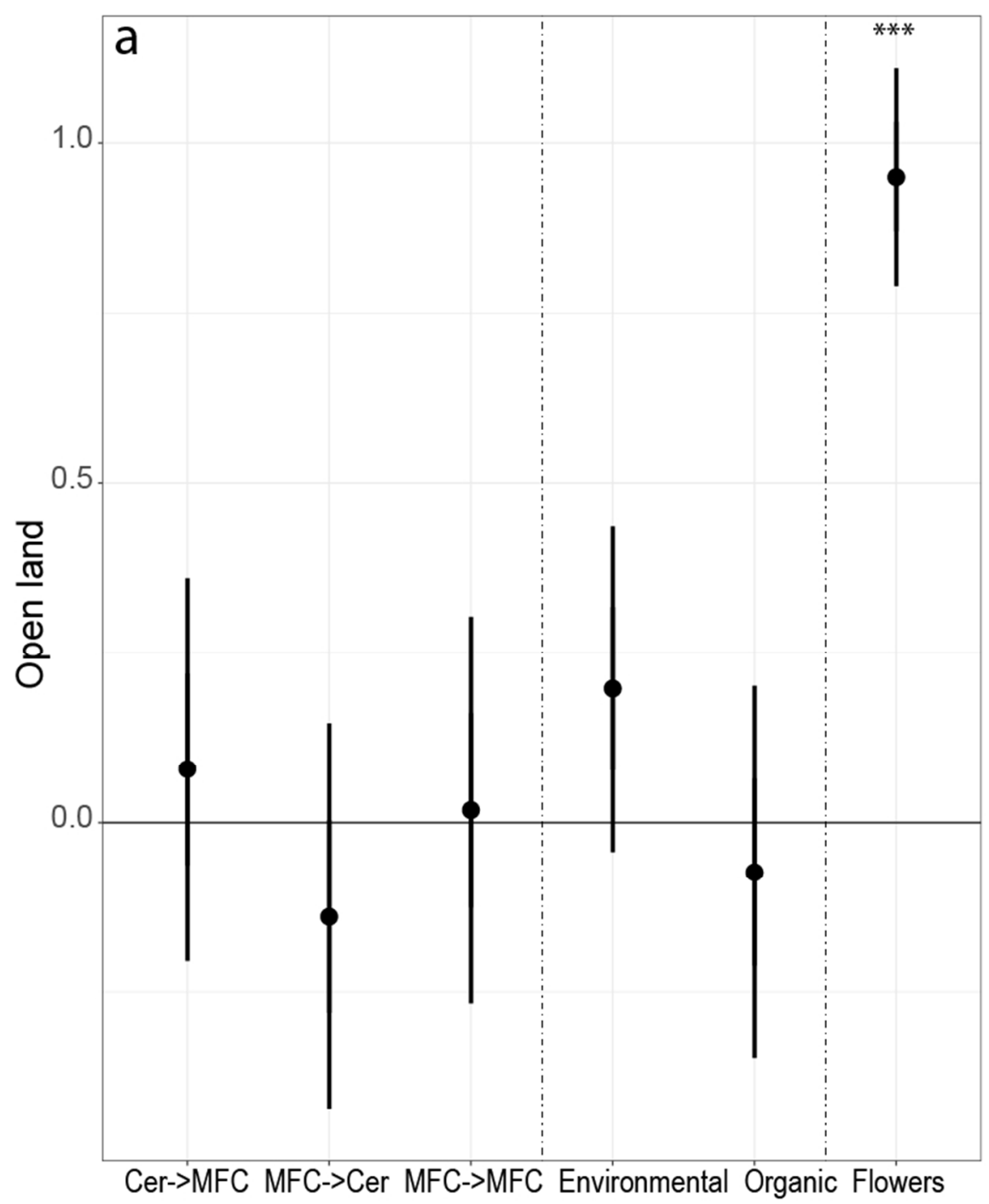

Fig. 4. Comparison of bumblebee abundances in field margins between different crop rotation types, management types, and effect of flower cover for species based on their habitat preference, i.e. (a) open land, (b) generalists, and (c) forest-scrub. The figure shows results from linear mixed-effects models ( $p$ value, lower and upper boundary of $95 \% \mathrm{CI}$ ). Indicated are effect sizes (y-axis) compared to the crop rotation type control group (cereal rollover field margins) and management type control group (conventional farming). The effect size is significantly different if the CIs do not overlap with zero. Asterisk symbols represent statistically significant $\mathrm{p}$-values below $0.05,0.01$, and $0.001(*, * *$ and, $* * *$ respectively). Cer $=$ cereals (all rye, oat, barley, triticale, and wheat fields), MFC = mass flowering crops (pea, bean, clover, alfalfa, sweet clover species, and oilseed rape), Environmental = environmentally friendly management, Organic $=$ organic farming, Flowers $=$ flower cover. 


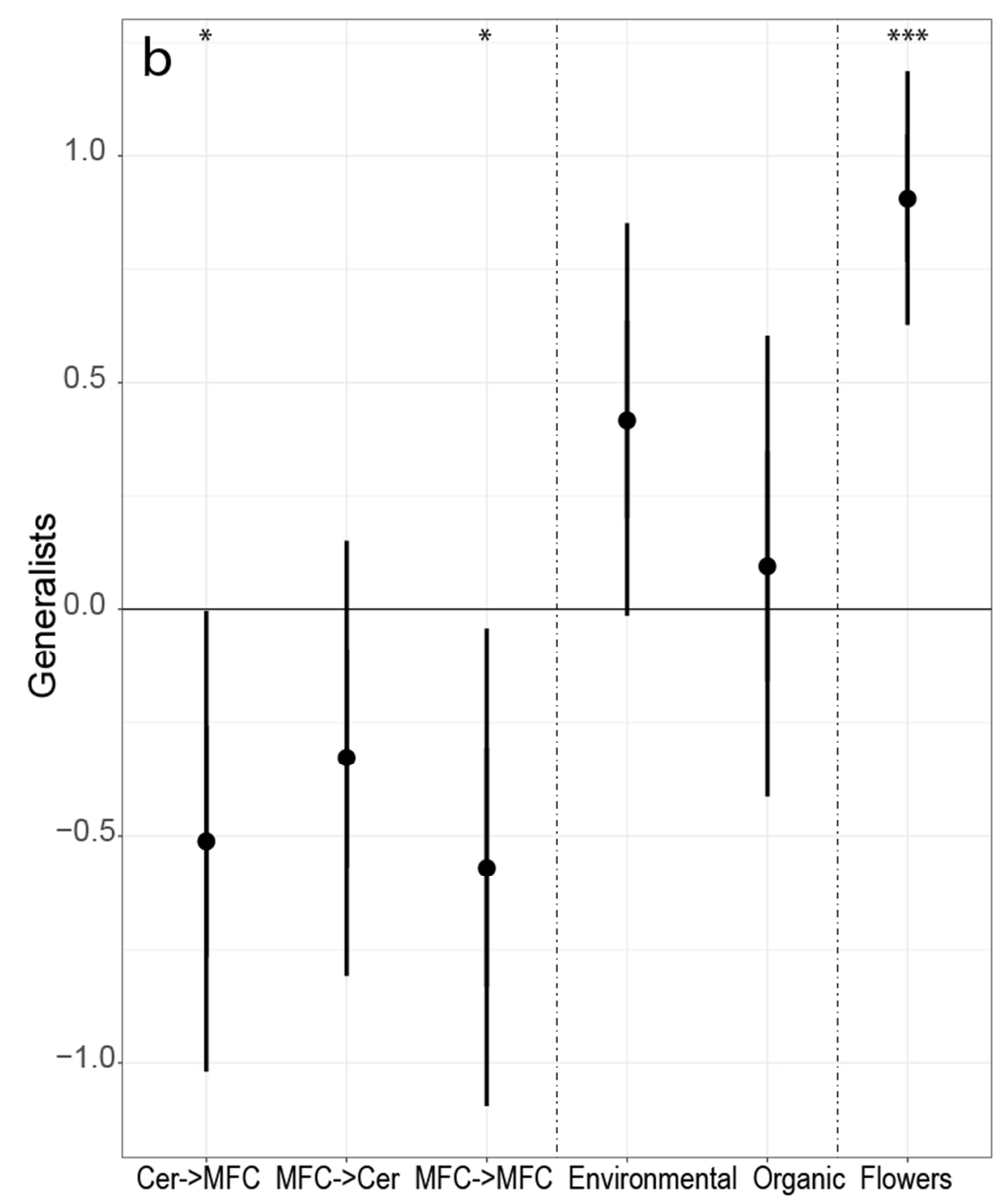

Figure $4 \mathrm{~b}$

$253 \times 279 \mathrm{~mm}(90 \times 90 \mathrm{DPI})$ 


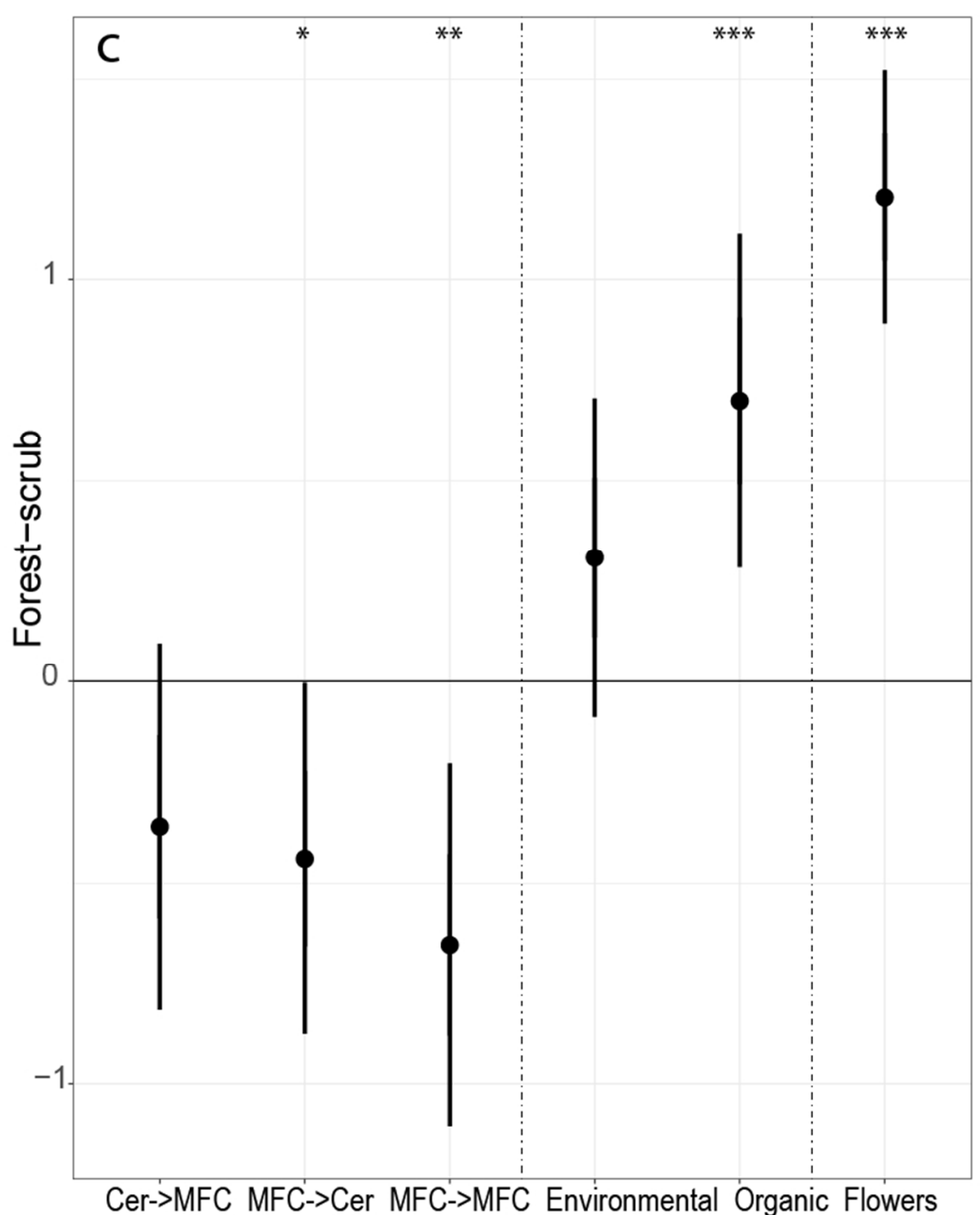

Figure $4 \mathrm{c}$

$253 \times 279 \mathrm{~mm}(90 \times 90 \mathrm{DPI})$ 


\section{Crop rotation and agri-environment schemes determine bumblebee communities via flower resources}

Riho Marja, Eneli Viik, Marika Mänd, James Phillips, Alexandra-Maria Klein, Péter Batáry

\section{SUPPORTING INFORMATION}

Table S1. Requirements of conventional farming (single area payment scheme) and two agri-environment schemes (environmentally friendly management, and organic farming), of the Estonian Rural Development Plan 2007-2013 (Estonian Rural Development Plan 2007-2013, 2010).

\begin{tabular}{|c|c|c|c|}
\hline Management type & Pre-requisites of applying for support & $\begin{array}{l}\text { Baseline requirements for obtaining agri- } \\
\text { environment support }\end{array}$ & $\begin{array}{l}\text { Additional requirements for obtaining agri-environment } \\
\text { support, specific to each scheme }\end{array}$ \\
\hline $\begin{array}{l}\text { Conventional } \\
\text { farming }\end{array}$ & $\begin{array}{l}\text { Cross-Compliance requirements. } \\
\text { Minimum } 1 \text { ha of agricultural land entered into } \\
\text { the register of agricultural support and } \\
\text { agricultural parcels. }\end{array}$ & & \\
\hline $\begin{array}{l}\text { Environmentally } \\
\text { friendly } \\
\text { management }\end{array}$ & $\begin{array}{l}\text { Cross-Compliance requirements. } \\
\text { Minimum requirements for the application of } \\
\text { fertilizers and plant protection products. } \\
\text { Self-employed person engaged in agriculture or } \\
\text { a legal person. } \\
\text { Minimum } 1 \text { ha of arable land entered into the } \\
\text { register of agricultural support and agricultural } \\
\text { parcels (permanent grassland is not eligible). } \\
\text { 5-year obligation. }\end{array}$ & $\begin{array}{l}\text { Keeping a field book. } \\
\text { Compiling a cropping or crop rotation plan. } \\
\text { Plant protection equipment have to pass a } \\
\text { technical inspection after every three years. } \\
\text { Agricultural crops are sown or planted by the } \\
15^{\text {th }} \text { of June (spread of weeds avoided) or the } \\
\text { agricultural land is kept as black fallow. } \\
\text { In certain parishes, at least } 30 \% \text { of the } \\
\text { agricultural land must remain under winter cover. } \\
\text { Restrictions on using nitrogen. } \\
\text { In certain cases, there have to be a grassland strip } \\
\text { of at least } 0.5 \text { meters or another kind of } \\
\text { landscape border element between the road and }\end{array}$ & $\begin{array}{l}\text { Basic scheme requirements: } \\
\text { Compiling a standard fertilization plan. } \\
\text { Requirement of a cropping or crop rotation plan (e.g. } 1^{\text {st }} \\
\text { November to } 31^{\text {st }} \text { March at least } 30 \% \text { under winter vegetation). } \\
\text { At least } 15 \% \text { of agricultural crops sown with certified seed. } \\
\text { Collection of soil samples once during the obligation period, } \\
\text { and in the case of manure storage facilities, manure samples. } \\
\text { To leave or establish a } 2-5 \mathrm{~m} \text { wide grassland strip with perennial } \\
\text { vegetation or other kind of landscape element between the field } \\
\text { and public road if the arable land area is larger than } 20 \text { ha (also } \\
\text { some more detailed requirements). } \\
\text { Cultural heritage sites and other valuable landscape elements }\end{array}$ \\
\hline
\end{tabular}




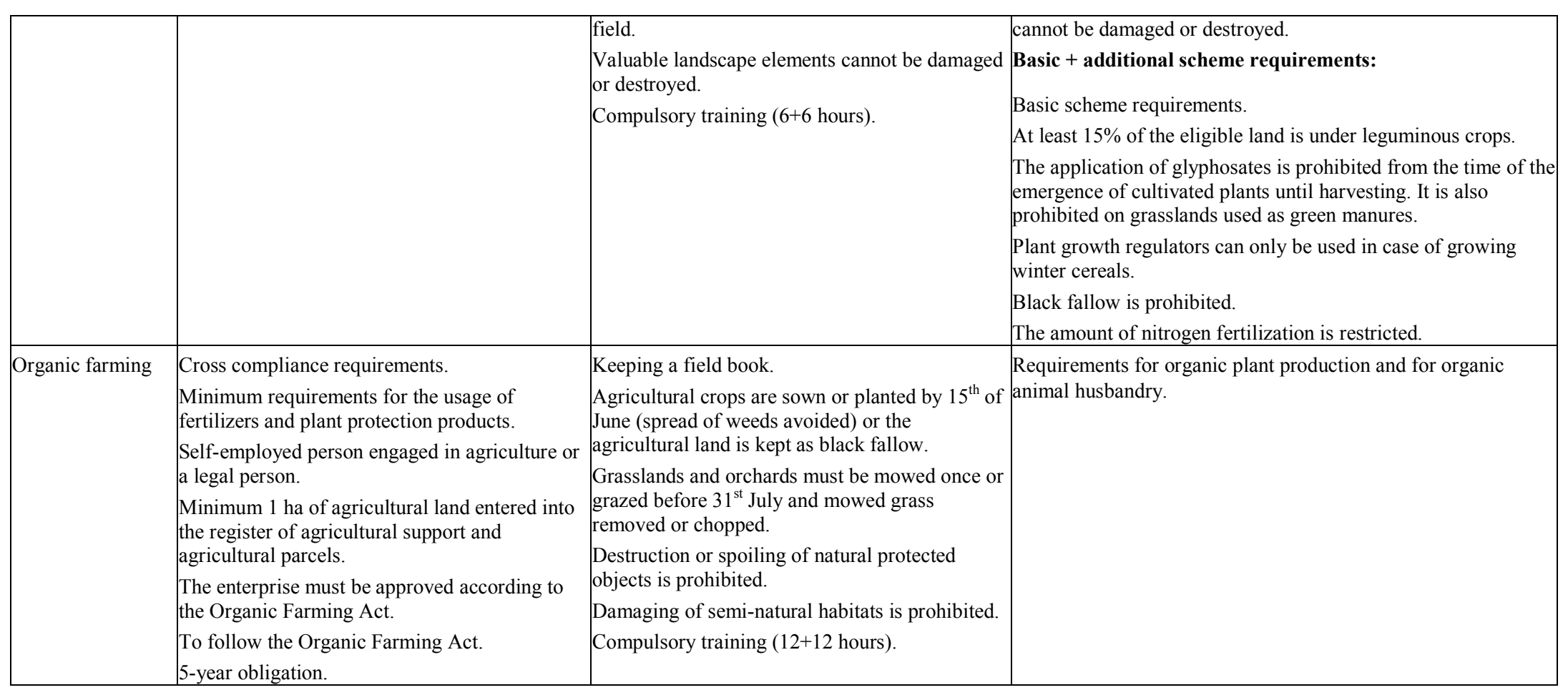

Estonian Rural Development Plan 2007-2013 (2010. URL: http://www.agri.ee/mak). 
Table S2. Flowering plant species known to be used by bumblebees for foraging in Estonian agricultural landscapes based on our 2014 unpublished survey.

\begin{tabular}{|c|c|c|}
\hline Plant species & Plant species & Plant species \\
\hline Aegopodium podagraria & Galopsis tetrahit & Symphytum officinale \\
\hline Anchusa arvensis & Geranium pratense & Trifolium hybridum \\
\hline Anchusa officinalis & Hieracium spp & Trifolium medium \\
\hline Arctium lappa & Hypericum maculatum & Trifolium pratense \\
\hline Arctium minus & Hypericum perforatum & Trifolium repens \\
\hline Arctium tomentosum & Knautia arvensis & Veronica longifolia \\
\hline Bunias orientalis & Lamium album & Vicia cracca \\
\hline Campanula cervicaria & Lamium hybridum & Vicia sepium \\
\hline Campanula glomerata & Lamium purpureum & Vicia villosa \\
\hline Campanula latifolia & Lathyrus pratensis & \\
\hline Campanula medium & Linaria vulgaris & \\
\hline Campanula persicifolia & Lonicera xylosteum & \\
\hline Campanula rapunculoides & Lotus corniculatus & \\
\hline Capsella bursa bastoris & Lupinus polyphyllus & \\
\hline Carduus crispus & Lythrum salicaria & \\
\hline Centaurea cyanus & Medicago lupulina & \\
\hline Centaurea jacea & Medicago sativa & \\
\hline Centaurea phrygia & Medicago varia & \\
\hline Centaurea scabiosa & Melampyrum nemorosum & \\
\hline Cirsium arvense & Melilotus albus & \\
\hline Cirsium heterophyllum & Mentha arvensis & \\
\hline Cirsium palustre & Odontites serotina & \\
\hline Consolida regalis & Odontites verna & \\
\hline Echium vulgare & Origanum vulgare & \\
\hline Epilobium angustifolium & Phacelia tanacetifolia & \\
\hline Fragaria vesca & Rubus idaeus & \\
\hline Galega orientalis & Silene alba & \\
\hline Galeopsis bifida & Silene vulgaris & \\
\hline Galeopsis speciosa & Sonchus oleraceus & \\
\hline Galeopsis tetrahit & Stachys palustris & \\
\hline Galium album & Symphytum asperum & \\
\hline
\end{tabular}


Table S3. Bumblebee species' traits based on tongue length, threat status, colony size, and main habitat type, and their abundance in our sample. Colony size information is based on Benton (2006), Pawlikowski (2008), von Hagen \& Aichhorn (2014), del Castillo et al. (2015), Weronika Banaszak-Cibicka (pers. comm.), and our unpublished data. Main habitat classification is based on Bäckman \& Tiainen (2002), Diaz-Forero et al. (2011), and our own unpublished data. Threatened species at a European scale were classified as vulnerable under the recent IUCN list (Nieto et al., 2014).

\begin{tabular}{|c|c|c|c|c|c|}
\hline Bumblebee species & Tongue length & Threat status & $\begin{array}{l}\text { Colony } \\
\text { size }\end{array}$ & $\begin{array}{l}\text { Main } \\
\text { habitat }\end{array}$ & $\begin{array}{l}\text { Total } \\
\text { number of } \\
\text { individuals }\end{array}$ \\
\hline Bombus confusus & short- or medium-tongued & threatened & small & generalist & 2 \\
\hline B. cryptarum & short- or medium-tongued & non-threatened & medium & generalist & 11 \\
\hline B. distinguendus & long-tongued & threatened & small & forest-scrub & 160 \\
\hline B. hortorum & long-tongued & non-threatened & medium & open & 526 \\
\hline B. humilis & short- or medium-tongued & non-threatened & small & open & 32 \\
\hline B. hypnorum & short- or medium-tongued & threatened & large & generalist & 240 \\
\hline B. jonellus & short- or medium-tongued & non-threatened & small & forest-scrub & 24 \\
\hline B. lapidarius & short- or medium-tongued & non-threatened & large & open & 1006 \\
\hline B. lucorum & short- or medium-tongued & non-threatened & large & open & 1150 \\
\hline B. muscorum & short- or medium-tongued & threatened & small & forest-scrub & 61 \\
\hline B. pascuorum & short- or medium-tongued & non-threatened & medium & forest-scrub & 785 \\
\hline B. pratorum & short- or medium-tongued & non-threatened & small & forest-scrub & 165 \\
\hline B. ruderarius & short- or medium-tongued & non-threatened & small & open & 486 \\
\hline B. schrencki & short- or medium-tongued & non-threatened & small & forest-scrub & 50 \\
\hline B. semenoviellus & short- or medium-tongued & non-threatened & small & open & 4 \\
\hline B. soroeensis & short- or medium-tongued & non-threatened & medium & generalist & 405 \\
\hline B. subterraneus & long-tongued & non-threatened & small & open & 46 \\
\hline B. sylvarum & short- or medium-tongued & non-threatened & small & open & 419 \\
\hline B. terrestris & short- or medium-tongued & non-threatened & large & open & 213 \\
\hline B. veteranus & short- or medium-tongued & non-threatened & small & open & 307 \\
\hline
\end{tabular}

\section{References}

Benton, T. (2006) Bumble bees: the natural history and identification of the species found in Britain. Collins, London.

Bäckman, J.-P. C. \& Tiainen, J. (2002) Habitat quality of field margins in a Finnish farmland area of bumblebees (Hymenoptera: Bombus and Psithyrus). Agriculture, Ecosystems \& Environment, 89, 53-68. 
del Castillo, R.C., Sanabria-Urbán, S. \& Serrano-Meneses, M.A. (2015) Trade-offs in the evolution of bumblebee colony and body size: a comparative analysis. Ecology and Evolution, 18, 3914-3926.

Diaz-Forero, I., Kuusemets, V., Mänd, M., Liivamägi, A., Kaart, T. \& Luig, J. (2011) Effects of forest habitats on the local abundance of bumblebee species: a landscape-scale study. Baltic Forestry, 17, 235-242.

Nieto, A., Roberts, S.P.M., Kemp, J., Rasmont, P., Kuhlmann, M., García Criado, M. et al. (2014) European Red List of bees. Luxembourg: Publication Office of the European Union.

Pawlikowski, T. (2008) A distribution atlas of bumblebees in Poland. Toruń. (in Polish).

von Hagen, E. \& Aichhorn, A. (2014) Hummeln: bestimmen, ansiedeln, vermehren, schützen. Fauna Verlag. (in German). 
Table S4. Investigated plant and bumblebee variables depending on crop rotation type (mean values and standard error of mean per transect section) and transect sections length mean values and standard error of mean. Cereal (all rye, oat, barley, triticale, and wheat fields), $\mathrm{MFC}=$ mass-flowering crops (pea, bean, clover, alfalfa, sweet clover species, and oilseed rape). Scale of flower cover 0-3: $0=$ no flowers suitable for bumblebees; $1=>0$ to $1 / 3$ of the area with flowers suitable for bumblebees; $2=1 / 3$ to $2 / 3$ with suitable flowers, $3=>2 / 3$ covered with suitable flowers.

\begin{tabular}{lcccc}
\hline & Cereal $\rightarrow$ cereal & Cereal $\rightarrow$ MFC & MFC $\rightarrow$ cereal & MFC $\rightarrow$ MFC \\
\hline Plants & & & & \\
Flower cover & $0.85 \pm 0.05$ & $1.32 \pm 0.06$ & $1.03 \pm 0.06$ & $1.36 \pm 0.06$ \\
\hline Bumblebees & & & & \\
Species richness & $3.92 \pm 0.25$ & $5.18 \pm 0.33$ & $4.31 \pm 0.29$ & $5.19 \pm 0.32$ \\
Abundance & $12.19 \pm 1.16$ & $18.64 \pm 2.42$ & $12.10 \pm 1.36$ & $17.89 \pm 1.67$ \\
Short-tongued abundance & $10.53 \pm 1.03$ & $16.69 \pm 2.11$ & $10.88 \pm 1.22$ & $15.55 \pm 1.47$ \\
Long-tongued abundance & $1.66 \pm 0.24$ & $1.95 \pm 0.40$ & $1.22 \pm 0.22$ & $2.34 \pm 0.38$ \\
Non-threatened abundance & $10.91 \pm 1.04$ & $17.53 \pm 2.22$ & $11.47 \pm 1.31$ & $16.46 \pm 1.53$ \\
Threatened abundance & $1.28 \pm 0.21$ & $1.11 \pm 0.29$ & $0.63 \pm 0.14$ & $1.44 \pm 0.28$ \\
Large colony abundance & $5.46 \pm 0.64$ & $8.45 \pm 1.23$ & $4.61 \pm 0.60$ & $7.47 \pm 0.92$ \\
Medium colony abundance & $3.68 \pm 0.41$ & $5.47 \pm 0.96$ & $3.61 \pm 0.48$ & $4.57 \pm 0.53$ \\
Small colony abundance & $3.05 \pm 0.40$ & $4.72 \pm 0.78$ & $3.87 \pm 0.54$ & $5.85 \pm 0.67$ \\
Open land abundance & $7.93 \pm 0.82$ & $12.91 \pm 1.66$ & $8.10 \pm 0.97$ & $12.86 \pm 1.30$ \\
Generalists abundance & $1.63 \pm 0.23$ & $1.87 \pm 0.34$ & $1.36 \pm 0.26$ & $1.68 \pm 0.26$ \\
Forest-scrub abundance & $2.62 \pm 0.36$ & $3.86 \pm 0.92$ & $2.64 \pm 0.43$ & $3.36 \pm 0.46$ \\
\hline Transect sections length & $227.5 \pm 11.7$ & $208.7 \pm 13.5$ & $223.6 \pm 13.7$ & $224.0 \pm 11.2$ \\
\hline
\end{tabular}


Table S5. Investigated plant and bumblebee variables depending on management type (mean values and standard error of mean per transect section) and transect sections length mean values and standard error of mean. Scale of flower cover 0-3: $0=$ no flowers suitable for bumblebees; $1=>0$ to $1 / 3$ of the area with flowers suitable for bumblebees; $2=1 / 3$ to $2 / 3$ with suitable flowers, $3=>2 / 3$ covered with suitable flowers.

\begin{tabular}{lccc}
\hline & $\begin{array}{c}\text { Conventional } \\
\text { farming }\end{array}$ & $\begin{array}{c}\text { Environmentally } \\
\text { friendly management }\end{array}$ & $\begin{array}{c}\text { Organic } \\
\text { farming }\end{array}$ \\
\hline Plants & $0.84 \pm 0.04$ & $1.23 \pm 0.05$ & $1.39 \pm 0.06$ \\
Flower cover & $3.61 \pm 0.21$ & $5.19 \pm 0.26$ & $5.31 \pm 0.30$ \\
\hline Bumblebees & $10.26 \pm 0.88$ & $18.88 \pm 1.70$ & $17.16 \pm 1.69$ \\
Species richness & $9.01 \pm 0.79$ & $16.61 \pm 1.48$ & $15.13 \pm 1.49$ \\
Abundance & $1.25 \pm 0.18$ & $2.27 \pm 0.34$ & $2.03 \pm 0.31$ \\
Short-tongued abundance & $9.47 \pm 0.81$ & $17.70 \pm 1.59$ & $15.58 \pm 1.51$ \\
Long-tongued abundance & $0.78 \pm 0.15$ & $1.19 \pm 0.20$ & $1.58 \pm 0.29$ \\
Non-threatened abundance & $4.69 \pm 0.46$ & $8.67 \pm 0.97$ & $6.31 \pm 0.77$ \\
Threatened abundance & $3.02 \pm 0.35$ & $5.13 \pm 0.53$ & $4.98 \pm 0.68$ \\
Large colony abundance & $2.55 \pm 0.34$ & $5.09 \pm 0.53$ & $5.86 \pm 0.69$ \\
Medium colony abundance & $7.14 \pm 0.66$ & $13.34 \pm 1.28$ & $11.28 \pm 1.15$ \\
Small colony abundance & $1.26 \pm 0.20$ & $2.11 \pm 0.27$ & $1.58 \pm 0.23$ \\
Open land abundance & $1.86 \pm 0.24$ & $3.43 \pm 0.43$ & $4.30 \pm 0.73$ \\
Generalists abundance & $236.0 \pm 10.9$ & $223.2 \pm 11.0$ & $201.8 \pm 9.8$ \\
Forest-scrub abundance & & & \\
\hline Transect sections length & & & \\
\hline & & & \\
\hline
\end{tabular}


Fig. S1. Illustrative photos of studied field margins.
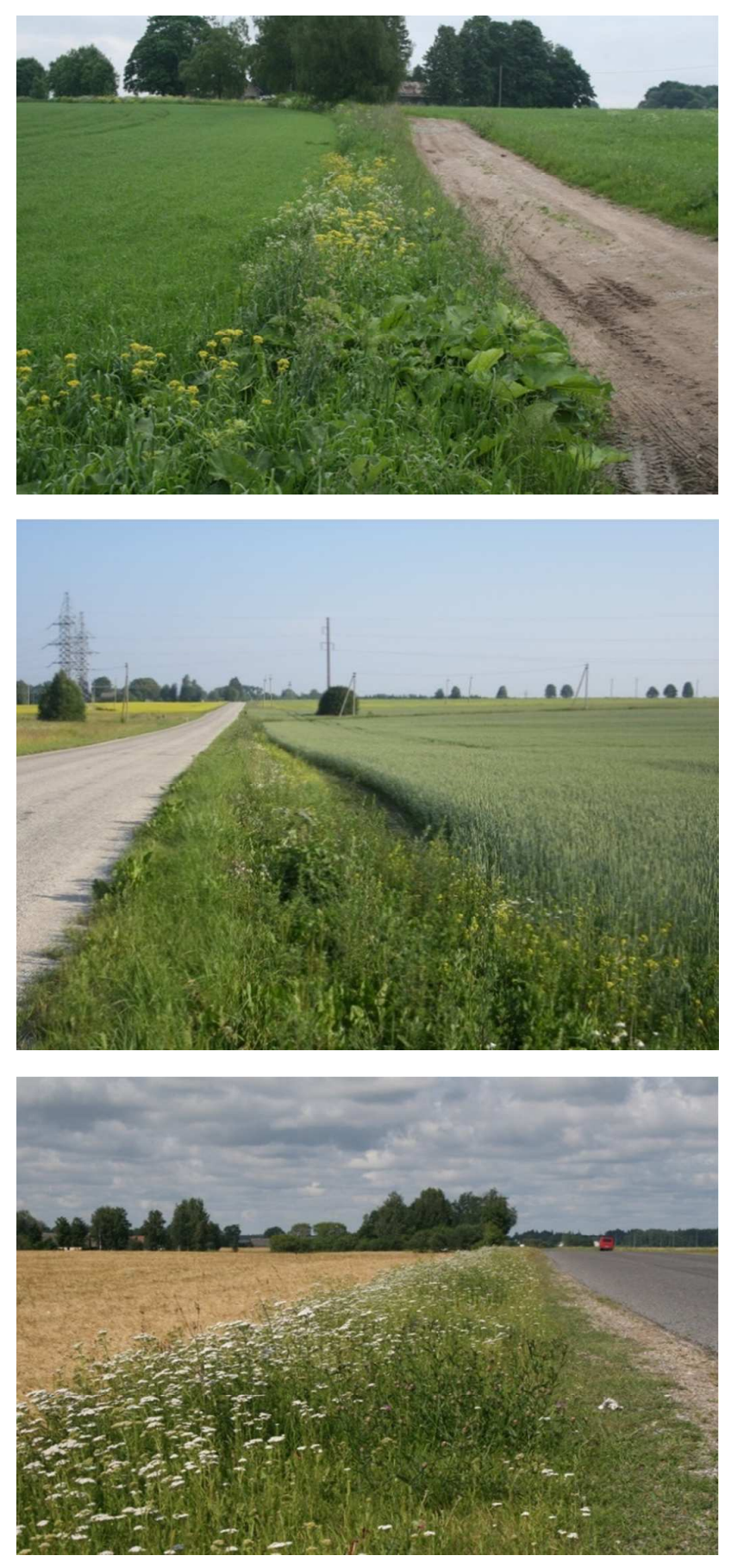


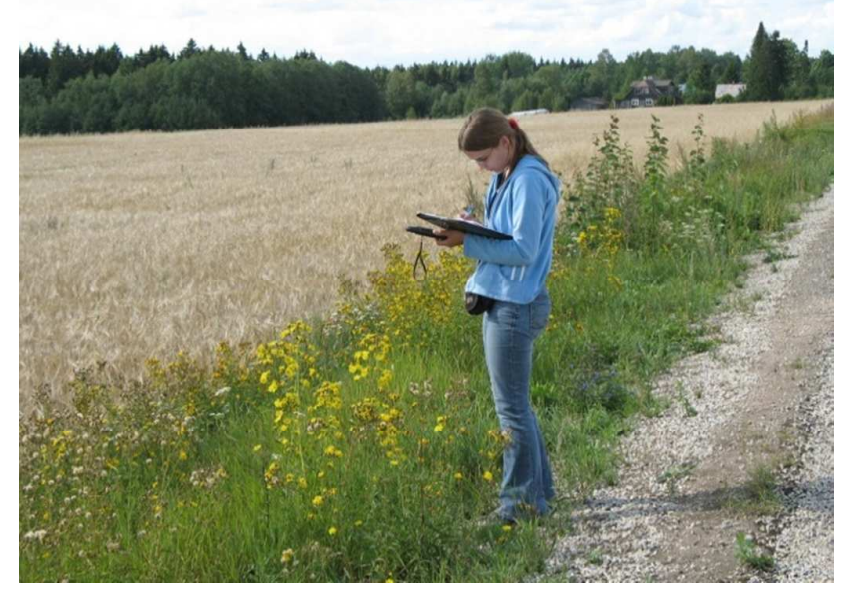


Fig. S2. Study sites (black dotes) in the two regions of Northern and Southern Estonia.

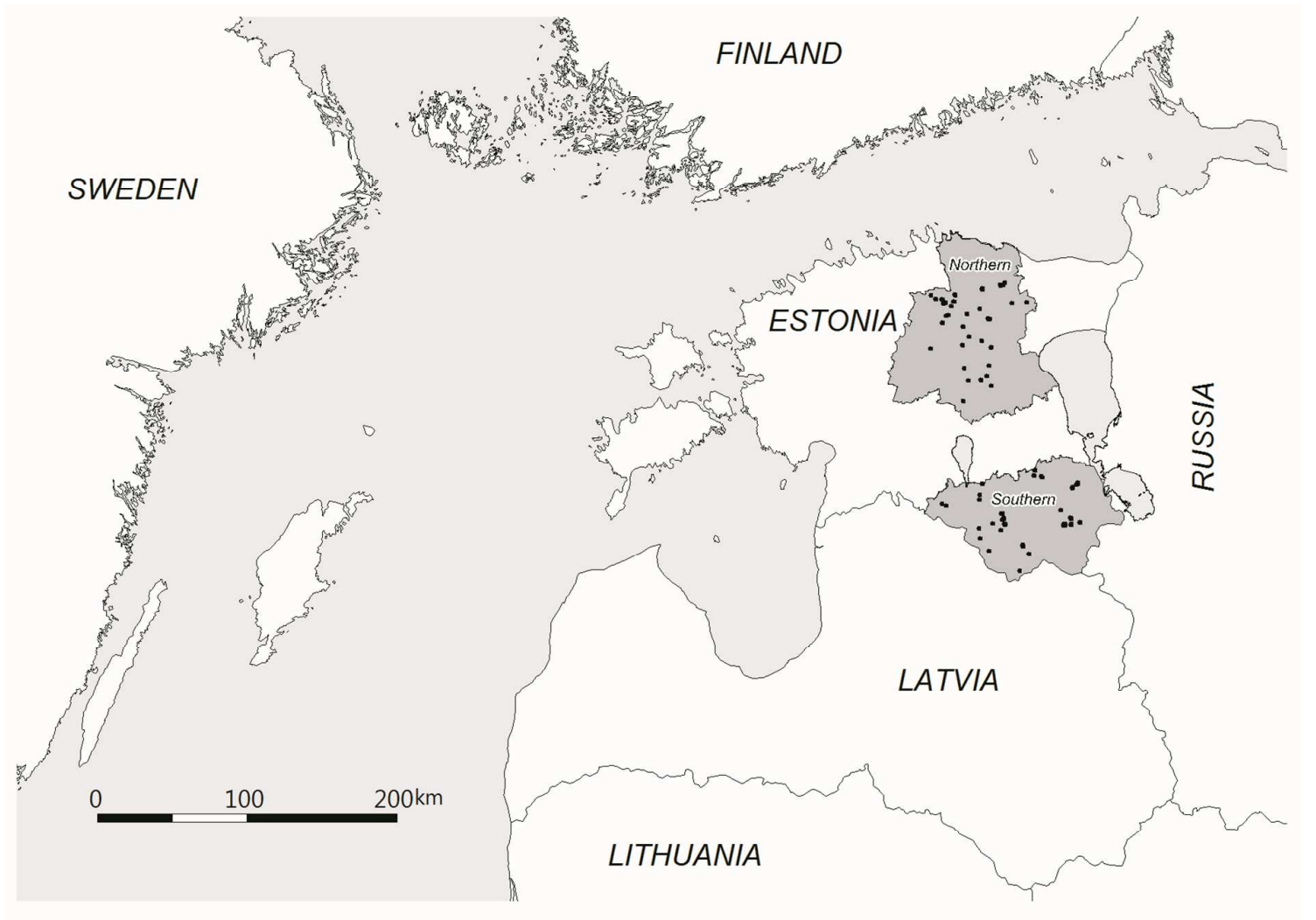


Fig. S3. Comparisons of bumblebee (a) species richness and (b) abundance in field margins between different crop rotation types, management types, and effect of flower cover. The figure shows results from linear mixed-effects models ( $p$-value, lower and upper boundary of 95\% CI). Indicated are effect sizes (y-axis) compared to the crop rotation type control group (cereal rollover field margins) and management type control group (conventional farming). The effect size is significantly different if the CIs do not overlap with zero. Asterisk symbols represent statistically significant $\mathrm{p}$-values below $0.05,0.01$, and $0.001\left(^{*}, * *\right.$, and $* * *$, respectively). Cer $=$ cereals (all rye, oat, barley, triticale, and wheat fields), MFC $=$ massflowering crops (pea, bean, clover, alfalfa, sweet clover species, and oilseed rape).

Environmental $=$ environmentally friendly management, Organic $=$ organic farming, Flowers $=$ flower cover.
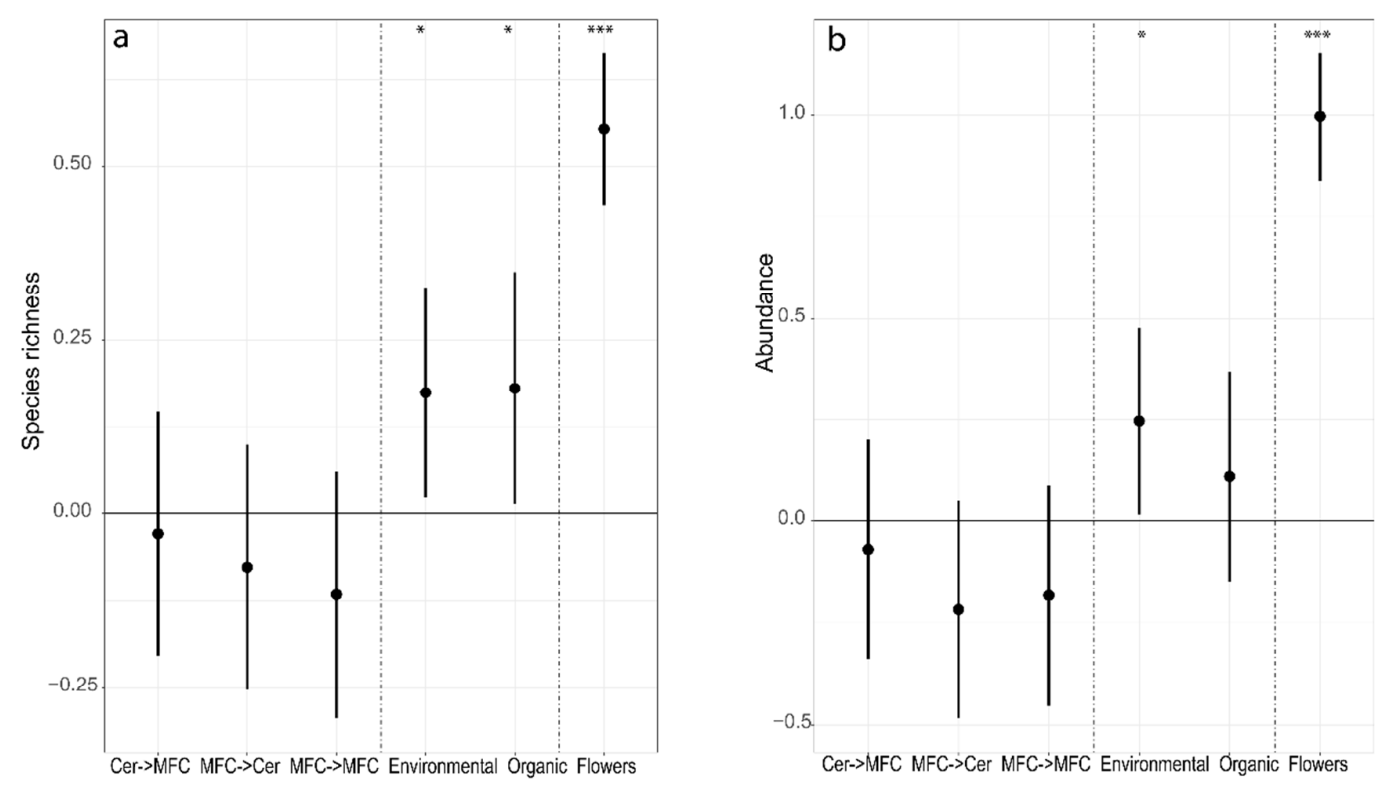
Fig. S4. Comparisons of bumblebee abundance in field margins between different crop rotation types, management types, and effect of flower cover for (a) short- and (b) longtongued bumblebee species. The figure shows results from linear mixed-effects models ( $\mathrm{p}$ value, lower and upper boundary of $95 \% \mathrm{CI}$ ). Indicated are effect sizes (y-axis) compared to the crop rotation type control group (cereal rollover field margins) and management type control group (conventional farming). The effect size is significantly different if the CIs do not overlap with zero. Asterisk symbols represent statistically significant $\mathrm{p}$-values below 0.05 , 0.01 , and $0.001(*, * *$, and $* * *$, respectively). Cer $=$ cereals (all rye, oat, barley, triticale, and wheat fields), MFC = mass-flowering crops (pea, bean, clover, alfalfa, sweet clover species, and oilseed rape). Environmental $=$ environmentally friendly management, Organic $=$ organic farming, Flowers $=$ flower cover.
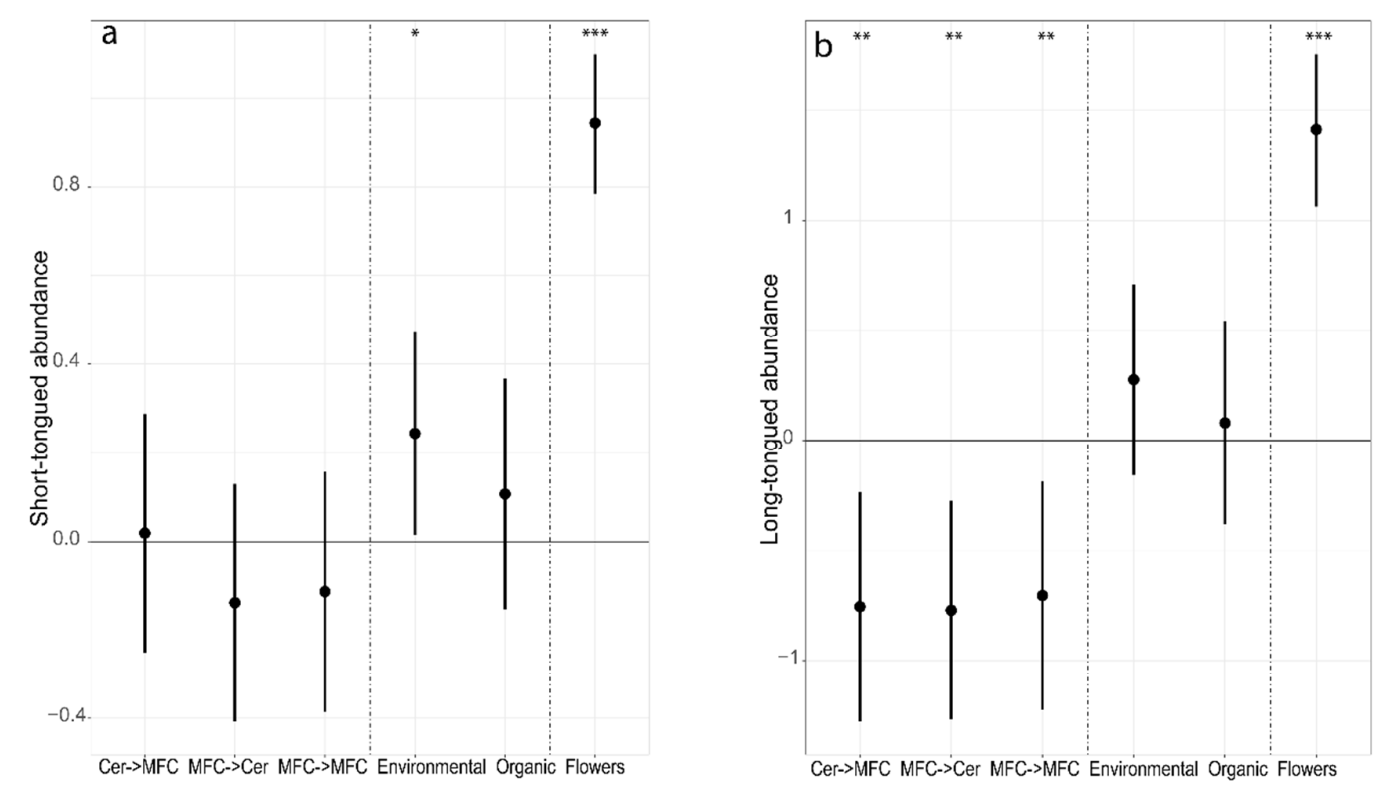